\title{
Lack of Protein S in mice causes embryonic lethal coagulopathy and vascular dysgenesis
}

\author{
Tal Burstyn-Cohen, ${ }^{1}$ Mary Jo Heeb, ${ }^{2}$ and Greg Lemke ${ }^{1}$ \\ ${ }^{1}$ Molecular Neurobiology Laboratory, The Salk Institute, La Jolla, California, USA. 'Department of Molecular and Experimental Medicine, \\ The Scripps Research Institute, La Jolla, California, USA.
}

\begin{abstract}
Protein S (ProS) is a blood anticoagulant encoded by the Pros1 gene, and ProS deficiencies are associated with venous thrombosis, stroke, and autoimmunity. These associations notwithstanding, the relative risk that reduced ProS expression confers in different disease settings has been difficult to assess without an animal model. We have now described a mouse model of ProS deficiency and shown that all $\operatorname{Pros}^{-/-}$mice die in utero, from a fulminant coagulopathy and associated hemorrhages. Although ProS is known to act as a cofactor for activated Protein C (aPC), plasma from Pros $1^{+/}$heterozygous mice exhibited accelerated thrombin generation independent of aPC, and Pros 1 mutants displayed defects in vessel development and function not seen in mice lacking protein C. Similar vascular defects appeared in mice in which Pros1 was conditionally deleted in vascular smooth muscle cells. Mutants in which Pros1 was deleted specifically in hepatocytes, which are thought to be the major source of ProS in the blood, were viable as adults and displayed less-severe coagulopathy without vascular dysgenesis. Finally, analysis of mutants in which Pros1 was deleted in endothelial cells indicated that these cells make a substantial contribution to circulating ProS. These results demonstrate that ProS is a pleiotropic anticoagulant with aPC-independent activities and highlight new roles for ProS in vascular development and homeostasis.
\end{abstract}

\section{Introduction}

Protein S (ProS) is a plasma glycoprotein that acts as a critical negative regulator of blood coagulation. It functions as an essential cofactor for activated protein $\mathrm{C}(\mathrm{aPC})$ in the degradation of coagulation factors FVa and FVIIIa (1-3) and thus operates at a central node in the coagulation cascade. In in vitro assays, ProS also binds directly to FVa, FVIIIa, and FXa $(4,5)$, although the extent to which it functions as an aPC-independent anticoagulant in vivo is debated.

The physiological importance of ProS is dramatically demonstrated by the catastrophic purpura fulminans that develops in the very rare newborns documented to be homozygous for ProS mutations (6). Individuals with less-severe ProS deficiencies due to heterozygous mutations or polymorphisms, of which more than 200 forms have been documented, are at elevated risk for deep vein thrombosis (DVT) and other life-threatening thrombotic events $(7,8)$. These same risks appear in the many SLE patients who display ProS deficiency (9).

Most of the ProS in plasma is thought to be synthesized in the liver by hepatocytes (10), but the Pros 1 gene is also expressed by several other cell types, including T cells, Sertoli cells, DCs, and macrophages (11). In these cells, ProS plays no apparent role in blood coagulation, but rather functions, together with the closely related protein Gas6, as an activating ligand for the TAM family of receptor tyrosine kinases ( $\underline{T} y r o 3, \underline{A} x l$, and $\underline{M} e r)$ (11-15). As a TAM agonist, ProS mediates a wide variety of regulatory phenomena, including the phagocytic clearance of apoptotic cells (16) and the attenuation and resolution of the innate immune response (11, 13). Of particular interest with regard to the results we report here, ProS is also a well-known product of vascular endothelial cells (ECs) $(17,18)$, which function in hemostasis, coagulation, and vascular development (19), and is also expressed by VSMCs (20). ProS

Conflict of interest: The authors have declared that no conflict of interest exists. Citation for this article: J. Clin. Invest. 119:2942-2953 (2009). doi:10.1172/JCI39325. triggers receptor activation in VSMCs and induces proliferation of these cells $(21,22)$, and VSMC expression of Axl has been found to be markedly elevated in response to vascular injury (23).

With the notable exception of the Pros 1 gene, whose locus has thus far proven refractory to targeting, all of the genes encoding critical components of the blood coagulation cascade have been inactivated in mice (ref. 24 and references cited therein; refs. 25-27). We have now added ProS to this complement of genetic reagents. We have engineered a conditional floxed knockout allele for the Pros 1 gene and then crossed mice carrying this allele with 4 different Cre driver lines. In these conditional mutants, the Pros 1 gene is inactivated (a) in all cells; (b) specifically in hepatocytes; (c) in endothelial and hematopoietic cells; and (d) specifically in VSMCs. Analysis of the dramatic but divergent phenotypes that appear in these lines, performed in concert with analysis of the vascular phenotypes displayed by the mouse Axl and Gas 6 knockouts, provides important new insights into ProS function in vivo.

\section{Results}

Generation of conditional floxed and knockout Pros1 alleles. We used recombineering methods in E. coli (see Methods) to generate a conditional floxed allele in which intronic loxP sites flank exons 11-15 of the mouse Pros1 gene (Figure 1). These exons encode a substantial fraction of the steroid hormone binding globulin (SHBG) domain of ProS (Figure 1, A-C), which is essential for ProS function, but are downstream of the Gla domain, which is required for binding to the phosphatidylserine that is displayed on the surface of platelets and apoptotic cells. This allele was introduced into the Pros 1 locus in mouse ES cells by homologous recombination, and these ES cells were then used to generate mice (Figure 1D; see Methods). Mice homozygous for the floxed allele (Pros $\left.1^{f / f l}\right)$ were in all respects normal and indistinguishable from wild-type mice.

We then crossed the Pros $1^{f l / f l}$ mice with an EIIA-Cre driver mouse line in which Cre recombinase is expressed in all cells from the 


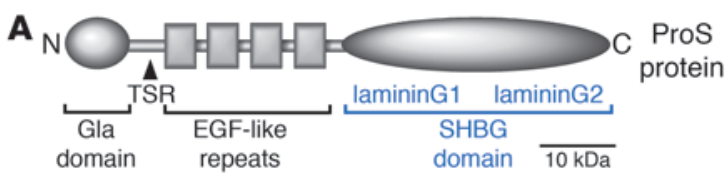

B

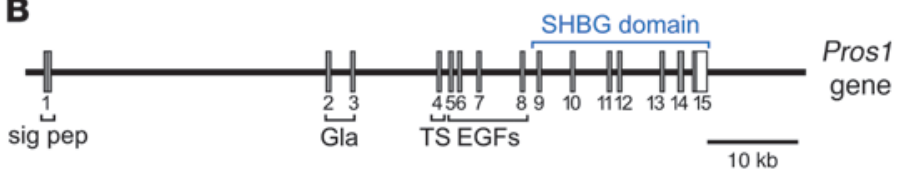

C

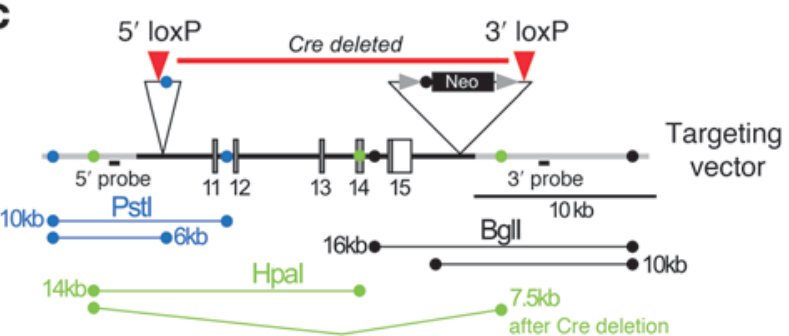

D

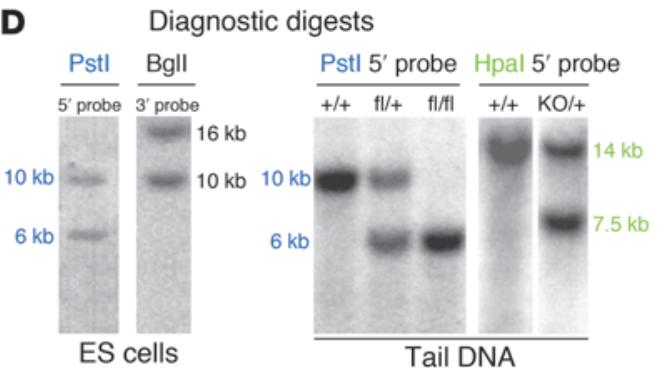

E

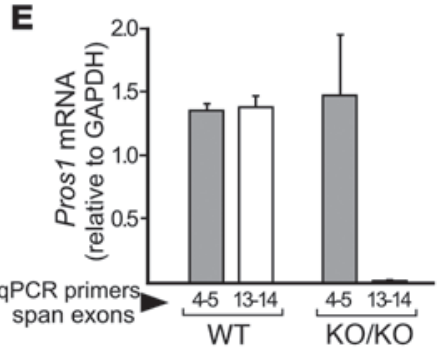

F

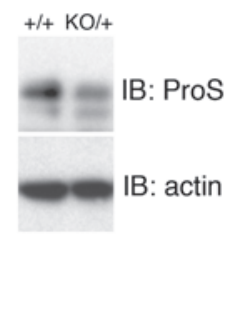

\section{Figure 1}

Mouse Pros1 gene targeting. (A) ProS structure: gamma carboxyglutamic acid (Gla) domain, thrombin-sensitive region (TSR), EGF-like repeats, and SHBG domain containing 2 laminin G repeats. (B) Mouse Pros 1 locus with exon 1 encoding the ProS signal peptide (sig pep). (C) Targeting vector: Exons 11-15 were flanked by loxP sites. Pstl (blue), Bgll (black), and Hpal (green) sites used to characterize targeting. (D) Southern blot of DNA from an ES cell clone, using Pstl and Bgll digests and the $5^{\prime}$ and $3^{\prime}$ external probes indicated in C (left 2 lanes). Pstl diagnostic digest of genomic DNA from WT (+/+), heterozygous (fl/+), and homozygous (fl/fl) floxed mice (middle 3 lanes). Crossing floxed mice to the EllA-Cre general deleter generated a KO Pros1 allele (far right lane). Hpal-digested genomic DNA from WT and KO/+ mice blotted and hybridized with the $5^{\prime}$ probe (right 2 lanes). (E) qPCR of Pros mRNA from E17.5 WT $(n=8)$ and KO $(n=6)$ embryos; mean \pm 1 SD. (F) Western blot of protein from WT $(+/+)$ and heterozygous Pros $1^{+/-}(\mathrm{KO} /+)$ mice, with an anti-ProS antibody generated against the amino terminus of the protein (upper blot) and anti- $\beta$-actin (lower blot). ProS appears as a full-length protein (upper band) and as a thrombin-cleaved form (lower band). Both lanes were run on the same gel but were noncontiguous. Transcripts from nontargeted aminoterminal exons 4-5 are present in Pros $1^{+/-}$heterozygotes (E) but apparently do not code for a stable protein. (See also Figure 9A for a related immunoblot.)

beginning of embryonic development (28) to generate a conventional complete ProS knockout (Figure 1, D-F). A substantial fraction of $\operatorname{Pros}^{+/-}$heterozygotes from this line were viable as adults (but see below), and these viable heterozygotes were fertile. In marked contrast, of 128 live-born neonates analyzed from heterozygote crosses, none were nulls (Pros1 $1^{-/-} ; n=0$ ). In addition, $\operatorname{Pros} 1^{+/-}$ heterozygotes themselves were underrepresented in the neonatal population, appearing at only approximately $55 \%$ of their expected Mendelian frequency $\left(n=67\right.$ Pros $^{+/-} ; n=61$ Pros $\left.^{+/+}\right)$. Genetic scoring of embryos prior to birth - between E10.5 and E13.5 - revealed that Pros $1^{-/-}$nulls were indeed present at the expected Mendelian ratio in this earlier population $\left(n=16 \operatorname{Pros}^{+/+}, n=49 \operatorname{Pros}^{1^{+-}}, n=18\right.$ Pros $\left.1^{-/}\right)$, indicating that ProS is dispensable for implantation and early embryogenesis but not for later stages of embryonic development. As expected, there were no detectable mRNA transcripts from targeted exons in these Pros $1^{-/}$embryos (Figure 1E), and Pros $1^{+/-}$heterozygotes express half the level of ProS protein relative to wild-type mice, as detected in Western blotting with an antibody generated against residues within the thrombin-sensitive cleavage site (Figure 1F; see Methods) and in ELISAs using two polyclonal antibodies (see below). No expression of an aberrantly truncated ProS protein was detected with the TS site antibody (see below).

Mid-embryonic lethality, macroscopic blood clots, and fulminant hemorrhages in complete Pros 1 knockouts. We found that all Pros $1^{-1-}$ mice die between E15.5 and E17.5, from a massive coagulopathy and associated hemorrhages (Figures 2, 3, 4). Inspection of intact mid- to late-gestation embryos revealed the presence of exceptionally large blood clots, together with fulminant hemorrhages, throughout the body (Figure 2B, asterisks). These anomalies were never seen in wild-type embryos (Figure 2A). Principal blood vessels of the embryo that were readily apparent in wild-type (Figure 2A; arrowheads) were not visible in Pros $1^{-/}$embryos (Figure 2B), consistent with their having been occluded by thrombi.

Analysis of sections from these E13.5-E15.5 embryos clarified this lethal Pros $1^{-/}$phenotype. Coronal brain sections of perfused Pros $1^{-/}$embryos revealed large, perfusion-resistant intravascular blood clots and pools of blood penetrating into the brain parenchyma. Compare, for example, the perfusion-cleared wild-type section in Figure 2C with the blood-filled section in Figure 2D. These coagulation anomalies were always associated with pronounced defects in central nervous system development, including grossly enlarged brain ventricles and a thinning of developing neocortical laminae (Figure 2, C and D). Perfused wild-type embryos contained cleared capillaries (Figure 2E), but perfused Pros $1^{-/-}$embryos were studded with capillaries that were occluded by clots containing aggregated fibrin and trapped blood cells (Figure 2F).

Coronal brain sections of unperfused E13.5 Pros1 $1^{-/-}$embryos, visualized using combined staining with $\mathrm{H} \& \mathrm{E}$ and differential Carstairs stain (see Methods), contained large pools of free blood cells, which frequently filled brain ventricles and parenchyma (Figure 3, A and B). Although blood vessels within the brain were prominently affected, damaged vessels, thrombi (Figure 3D), 

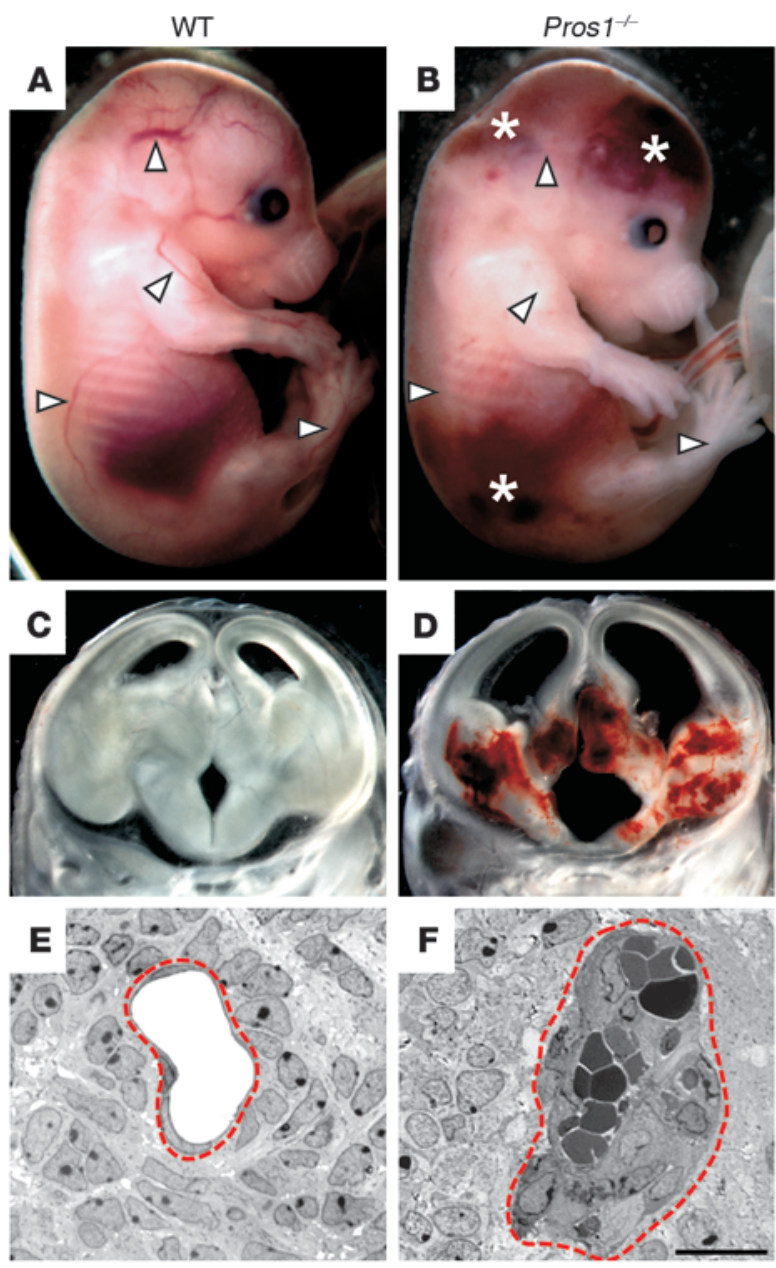

and extravascular hemorrhagic blood (Figure 3E) were observed throughout Pros $1^{-/-}$embryos. Cross sections of mutants frequently displayed evidence of blood leakage (Figure 3D; compare with the wild-type section in Figure 3C), with interrupted endothelial lin-

\section{Figure 2}

Lethal embryonic coagulopathy in ProS-deficient mice. Wild-type (A, C, and E) and Pros 1-l- littermates (B, D, and F) at E15.5. (A and B) Principal superficial blood vessels that are readily visible in WT (A, arrowheads; $n=8$ ) are not visible in Pros $1^{-1-}$ littermates (B, arrowheads; $n=10)$. Pros $1^{-/-}$embryos present with macroscopic thrombi (B, asterisks). (C and $\mathbf{D})$ Coronal brain sections $(300 \mu \mathrm{m})$ of perfused WT and Pros $1^{-/-}$embryos, respectively. Perfusion of WT brain yields clear tissue (C), but intravascular thrombi render vessels perfusion resistant in Pros $1^{-/}$brain tissue, and hemorrhages are prominent (D). (E and F) Perfusion-drained WT (E) and occluded, perfusion-resistant Pros 1-/(F) capillaries in 1- $\mu \mathrm{m}$ sections of perfused embryonic brains; white and red blood cells are trapped in a fibrin mesh. Red dashed lines delineate the boundaries of the microvessels. Scale bar in $\mathbf{F}$ applies to all panels: $500 \mu \mathrm{m}$ in $\mathbf{A}-\mathbf{D} ; 20 \mu \mathrm{m}$ in $\mathbf{E}$ and $\mathbf{F}$.

ings of thin-walled vessels through which blood cells leaked into surrounding tissues (arrowheads in Figure 3D). These tissues presented with pyknotic nuclei (arrows in Figure 3D), typical of cells killed by ischemic insult.

Analysis of sections of perfusion-cleared E15.5 embryos using the same combined H\&E/differential Carstairs staining method (Figure 4) identified fibrin clots within blood vessels (arrowheads in Figure 4, B, D, F, and H), as well as loose blood cells in all of the tissues of Pros $^{-/-}$embryos that we analyzed. These included the body wall (Figure 4B), brain, spinal cord (Figure 4D; note the large number of free blood cells that typically accumulated within the central canal), vascular plexus (Figure 4F), lungs, and liver (Figure $4 \mathrm{H}$; note the trapped, perfusion-resistant blood cells evident in all tissues). Fibrin clots and loose blood were not observed in any wild-type embryonic tissue (Figure 4, A, C, E, and G).

Accelerated clotting in plasma from Pros $1^{+/}$beterozygotes. Although Pros $1^{+/-}$heterozygotes were viable and fertile as adults, the embryonic lethal phenotypes of Pros $1^{-/-}$homozygotes, together with the reduced number of $\operatorname{Pros}^{+/-}$heterozygous neonates and the coagulopathies associated with human ProS deficiencies, suggested that adult $\operatorname{Pros}^{+/-}$heterozygotes should exhibit defects in blood coagulation. We measured coagulation using two different assays for ProS activity. First, we developed an aPC cofactor assay for ProS in plasma

\section{Figure 3}

Severe hemorrhages and thrombi in Pros $1^{-/-}$embryos. (A and B) Carstairs staining of $10-\mu \mathrm{m}$ coronal cryosections from nonperfused E13.5 embryo heads. Clotted blood cells stain magentapurple; collagen, blue; and tissue, purple-blue. (A) Intact WT tissue with normal ventricles, no hemorrhages, and no clots. (B) Pros $1^{-/-}$heads are hemorrhagic, with blood clots, enlarged brain ventricles, and prominent penetration of blood into the brain parenchyma. (C-E) H\&E staining of paraffin sections $(4 \mu \mathrm{m})$ from nonperfused WT (C) and Pros 1 $1^{-1-}$ embryos (D and E). Vessel walls are thick and well formed in WT (C) but are thin and discontinuous in Pros 1-/- embryos (D), enabling leakage of blood cells into the surrounding tissue (D, arrowheads), which presents with pyknotic nuclei typical of ischemic damage (D, arrows). The vessel in D contains a thrombus (center). (E) Subectodermal, superficial hemorrhages are indicative of severe blood loss in Pros $^{-1-}$ mice. Scale bar in E applies to all panels: 1,000 $\mu \mathrm{m}$ (A and B); $50 \mu \mathrm{m}$ (C and D); and $100 \mu \mathrm{m}$ (E).
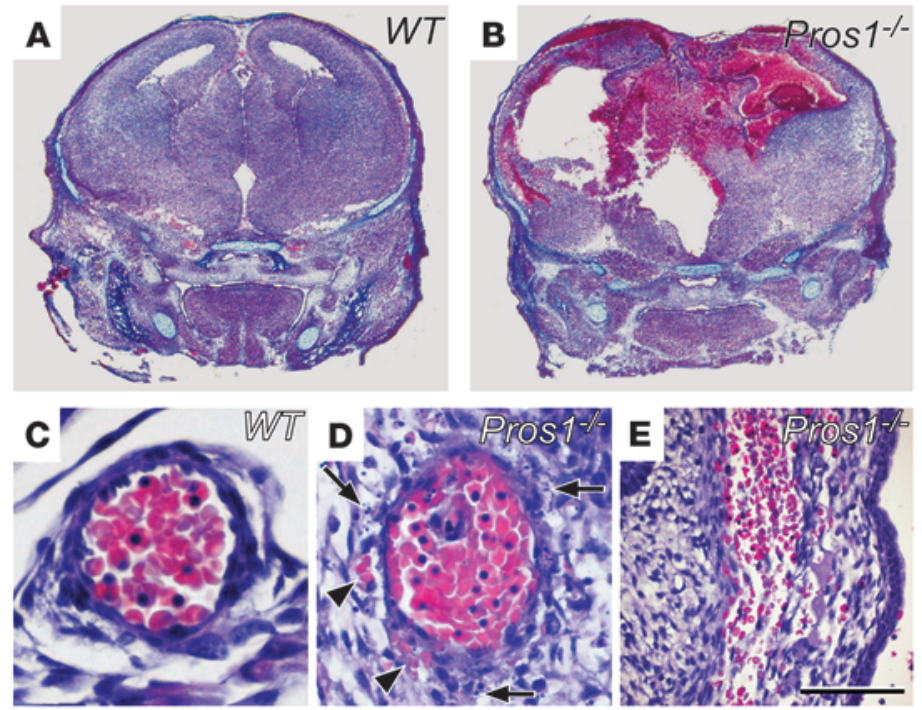

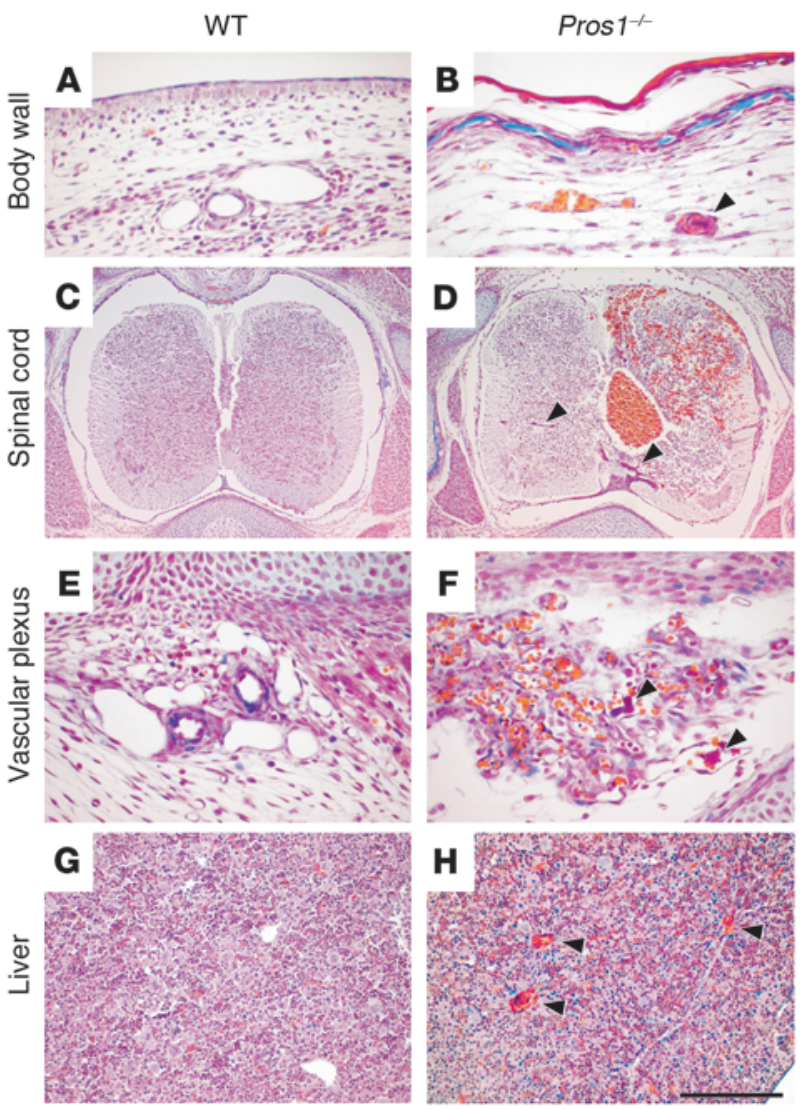

and using this assay determined that $\operatorname{Pros} 1^{+/-}$mouse plasmas have a mean of $47 \%$ of the aPC cofactor activity of wild-type mouse plasmas (Figure 5A). Importantly, however, we found that base clot times without exogenous aPC were also significantly shorter (Figure 5B), indicative of a reduction in direct ProS anticoagulant activity. This "direct activity" is interesting, given that protein C (PC) is a zymogen of an active protease that cleaves FVa and FVIIIa, whereas ProS is not. Base clot times were unaffected by the inclusion of neutralizing antibodies against mouse PC (data not shown).

To quantify this direct activity, we developed a fluorescencebased assay for aPC-independent ProS anticoagulant activity, using thrombin generation profiles after a stimulus of prothrombinase complex (FXa/FVa) (Figure 5C). Both the lag time to thrombin generation (Figure 5D) and the time to peak thrombin generation (Figure 5C) were significantly reduced in $\mathrm{Pros}^{+/-}$mice, indicating

\section{Figure 5}

ProS activity in mouse plasmas. (A) aPC cofactor activity in mouse plasmas. Mean prolongation of clot time by aPC in Pros $1^{+/+}$plasmas (49.1 seconds) was taken as $100 \%$ aPC cofactor activity of ProS, and prolongations of individual plasmas were converted to \% aPC cofactor activity. Points represent individual mouse plasmas. (B) Base clot times in the same assay as in A, but without aPC added. (C) ProSdirect anticoagulant activity in mouse plasmas. Thrombin generation profiles for 2 representative Pros $1^{+/+}$and 2 representative Pros $1^{+/-}$ mouse plasmas, after a stimulus of prothrombinase complex. (D) Lag times from profiles similar to those displayed in C, for 4 Pros $1^{+/+}$mice and 5 Pros $1^{+/-}$mice. Statistical difference between cohorts of Pros $1^{+/+}$ mice and Pros ${ }^{+/-}$is shown in A, B, and D.

\section{Figure 4}

Pros $1^{-/}$embryos present with a massive disseminated hypercoagulopathy and associated hemorrhages. Carstairs differential stain of perfused E15.5 WT (A, C, E, and G) and $\operatorname{Pros}^{-1-}(\mathbf{B}, \mathbf{D}, \mathbf{F}$, and $\mathbf{H})$ littermates stains loose blood cells yellow-orange; fibrin clots, magentapurple; and collagen, blue. All WT vessels were cleared by perfusion in every tissue examined. In contrast, every Pros $1^{-/}$tissue displayed perfusion-resistant blood-bearing vessels with yellow-stained blood cells and magenta fibrin-positive clots (arrowheads in $\mathbf{B}, \mathbf{D}, \mathbf{F}$, and $\mathbf{H}$ ). (D) Note the massive hemorrhages present in the spinal cord lumen (central canal) and the right dorsal quadrant (yellow-orange stain). Scale bar in $\mathbf{H}$ applies to all panels: $400 \mu \mathrm{m}$ in $\mathbf{C}$ and $\mathbf{D}$; $100 \mu \mathrm{m}$ in A, $\mathrm{B}$, and $\mathbf{E}-\mathbf{H}$.

that these mice are prothrombogenic. A neutralizing antibody against mouse aPC was included in the assays to exclude any contribution of aPC cofactor activity (see Methods). The assays were unaffected by the aPC antibody; by neutralizing antibody against tissue factor pathway inhibitor (TFPI); or by corn trypsin inhibitor, an inhibitor of the contact pathway of coagulation (data not shown). Together, these results provide the first in vivo genetic evidence to our knowledge that ProS inhibition of prothrombinase activity is both aPC and TFPI independent.

Genetic evidence for ProS action during vascular development and homeostasis. ProS was first identified as a ligand for the TAM receptors through its activity in medium conditioned by bovine vascular ECs (ABAE cells) and its activity in serum (12). As noted above, ECderived ProS has potent trophic effects on cultured VSMCs (21, 22), which also produce their own ProS (20). At the same time, the development and functional integrity of blood vessels are both tied to blood flow, and thromboses almost invariably result in disturbed flow, which in turn induces an EC response that leads to vascular inflammation and remodeling $(29,30)$. We therefore examined E13.5 Pros1 $1^{-/}$embryos for anomalies in vessel development and function. Immunohistochemistry with the VSMC

A

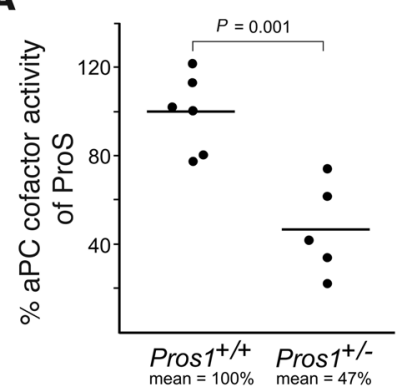

C

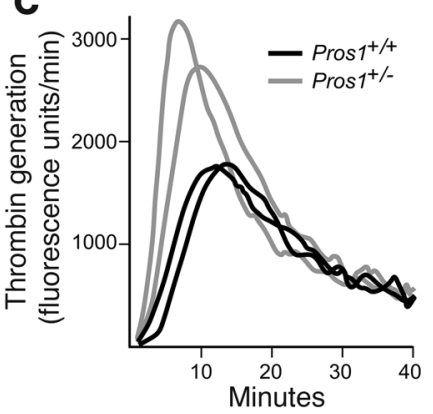

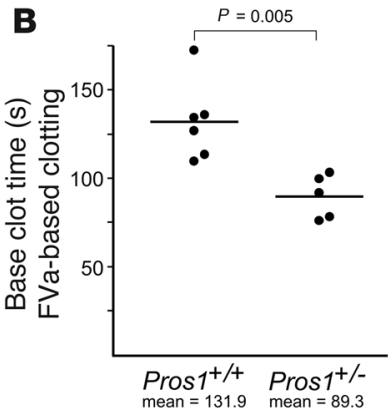

D

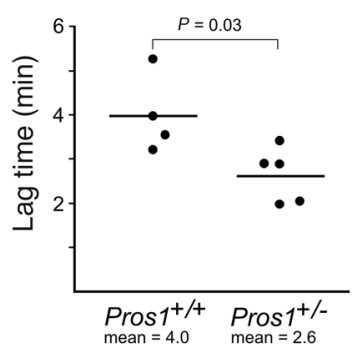



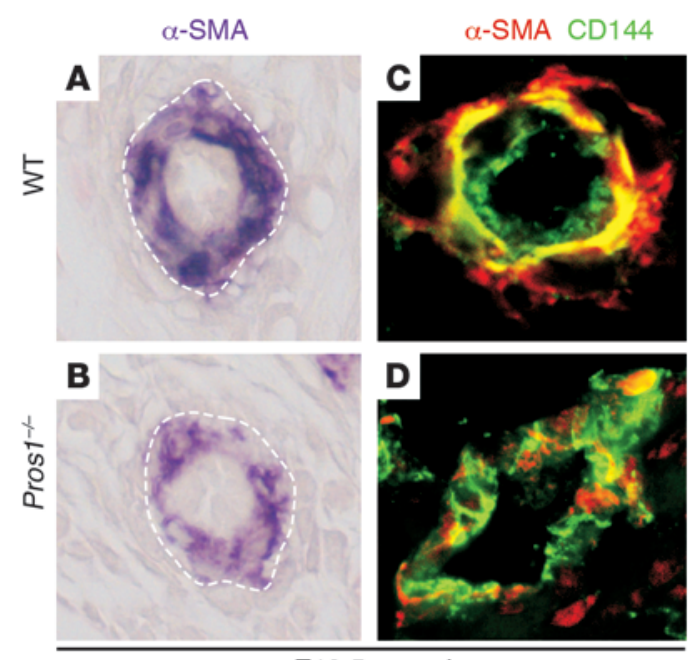

E13.5 vessel
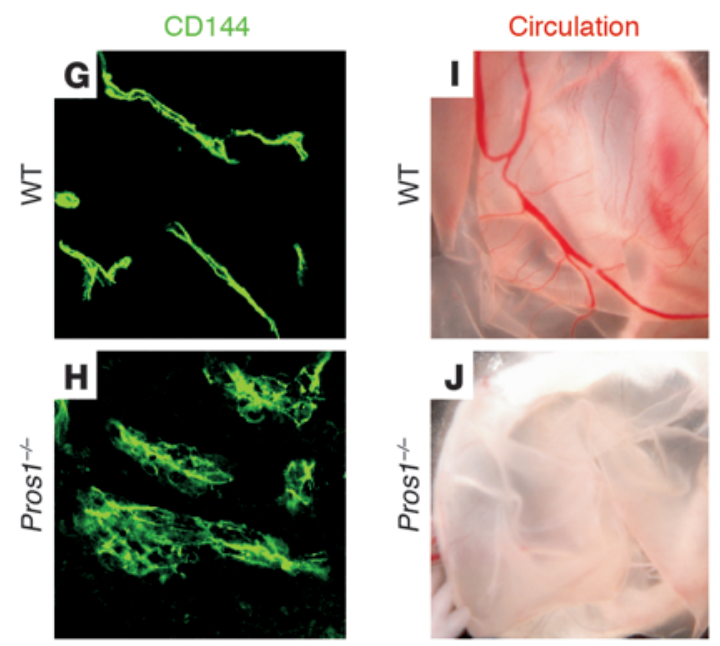

E13.5 microvasculature

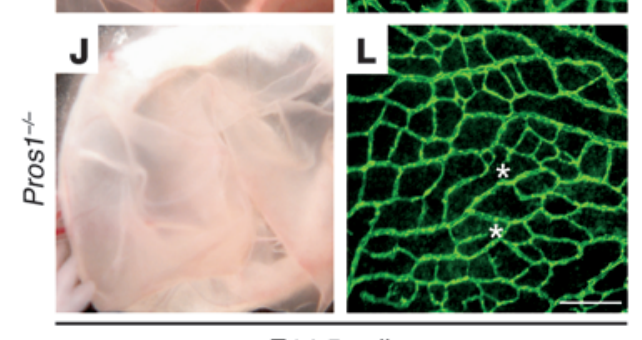

E14.5 yolk sac

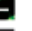

Fibrin CD31
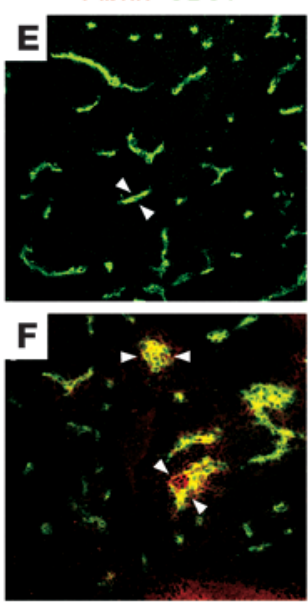

E15.5 microvasculature

CD31

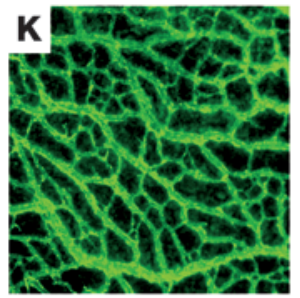

\section{.}

\section{Figure 6}

Immunohistochemical analysis of embryonic vasculature. (A and B) Sections of dorsal superficial artery stained with the smooth muscle cell marker $\alpha$-SMA. Vessels are delineated by dashed lines. VSMCs show intense $\alpha$-SMA staining throughout the circumference of the WT vessel (A) but only weak noncontinuous staining in the Pros $1^{-/-}$ vessel (B). (C and D) Double staining of ECs with CD144/ VE-cadherin (green) and VSMCs with $\alpha$-SMA (red). (C) WT arterioles have a luminal EC layer surrounded by a VSMC layer. (D) Pros $1^{-/-}$arteriole shows only residual $\alpha$-SMA signal and disorganized, nonuniform endothelial and VSMC marker staining. (E and F) Double staining of spinal cord microvasculature for CD31/PECAM-1 (green) and fibrin (red). (E) WT small-diameter vessels (apposed arrowheads) without fibrin clots. (F) Pros $1^{-/-}$spinal cord vasculature with fibrin-positive immunoreactivity within vessels and aneurysms (apposed arrowheads). ( $\mathbf{G}$ and $\mathbf{H}$ ) Vessel ECs revealed by CD144/VE-cadherin in brain vasculature. (G) WT tissue shows elongated and uniform vessels, with tight interendothelial junctions. (H) Pros $1^{-/-}$mice fail to form tight vessels, with ECs dispersed in clusters. (I and J) Yolk sac vasculature. Blood-filled vessels are seen in WT (I) but not in Pros1-/- yolk sac (J). (K and L) PECAM-1/CD31 immunoreactivity in yolk sac. CD31 staining reveals an intricate vascular network in WT yolk sac (K), but $P$ ros $1^{-/-}$yolk sac vasculature shows reduced vascular density, smaller-caliber vessels, and blind ends that fail to anastomose (asterisks). Scale bar in $\mathbf{L}$ applies to all panels: $150 \mu \mathrm{m}$ in A, B, E, F, K, and L; $40 \mu \mathrm{m}$ in C, D, G, and $\mathbf{H} ; 500 \mu \mathrm{m}$ in $\mathbf{I}$ and $\mathbf{J}$. marker $\alpha$-SMA demonstrated reduced and dispersed staining of developing Pros $1^{-/}$vessel walls (Figure 6, A-D). Reduced staining for $\alpha$-SMA was consistently seen in all Pros $1^{-/}$embryos analyzed but was more prominent in VSMC-rich arteries. Combined staining with anti-CD144 (vascular endothelial cadherin [VE-cadherin]) revealed well-formed vessels with segregated endothelial and muscle expression in wild-type E13.5 embryos but diminished and intermixed expression of these markers in Pros $1^{-/}$embryos (Figure 6, C and D). Staining of E15.5 Pros $1^{-/-}$spinal cord microvasculature with antibodies against CD31 (the EC adhesion protein PECAM-1) and fibrin, the major constituent of blood clots, revealed a substantial reduction in CD31 signal in poorly formed microvessels, with associated intravascular blood clots (Figure 6, $\mathrm{E}$ and $\mathrm{F}$ ). In addition, spinal cord vessels were enlarged (Figure 6, $\mathrm{E}$ and F, arrowheads). E13.5 brain microvasculature also displayed a routinely dispersed and disaggregated vessel structure in Pros $1^{-1-}$ mice, whereas elongated tubular vessels were observed in wild-type littermates (Figure 6, G and H). Defects in vessel development, integrity, and function were also evident in the embryonic yolk sacs. Blood-filled vessels were impossible to discern visually when yolk sacs were isolated from E14.5 $\mathrm{Pros}^{-/-}$mice, probably due to occluded circulation (Figure 6, I and J). Staining with anti-
CD31 revealed that these vessels were indeed present but poorly formed (Figure 6, K and L), with a 33\% reduction in CD31 staining intensity, a $40 \%$ reduction in branch frequency, and an absence of normal hierarchical branching morphology.

Although the embryonic lethality of $\operatorname{Pros}^{1^{-/}}$mice obviously precluded an analysis of vessel function in adult mice, we reasoned that defects in vessel integrity might also be apparent in adult Pros $1^{+/-}$heterozygotes, since Pros $1^{+/-}$heterozygous embryos frequently exhibited examples of both normal and aberrant vessel morphology and organization in the same embryo, as visualized by $\alpha$-SMA and CD144 immunostaining (Figure 7, A and B). Adult vessel physiology is directly affected by mechanotransduction of the circulation, and ECs are very sensitive to the impaired blood flow that results from atherosclerotic plaques and thromboses $(29,31)$. We therefore assessed blood vessel integrity and function in adult mice by injecting Evans blue (EB) dye into the tail vein and then monitoring the appearance of dye in various tissues 1 hour later. EB binds tightly to serum albumin and is widely used as a tracer to detect leakage of plasma macromolecules into tissues. In a normal vasculature, EB-bound albumin is confined to the circulation and does not leak into tissue parenchyma (32). Pros $1^{+/-}$mice, however, typically exhibited striking, 

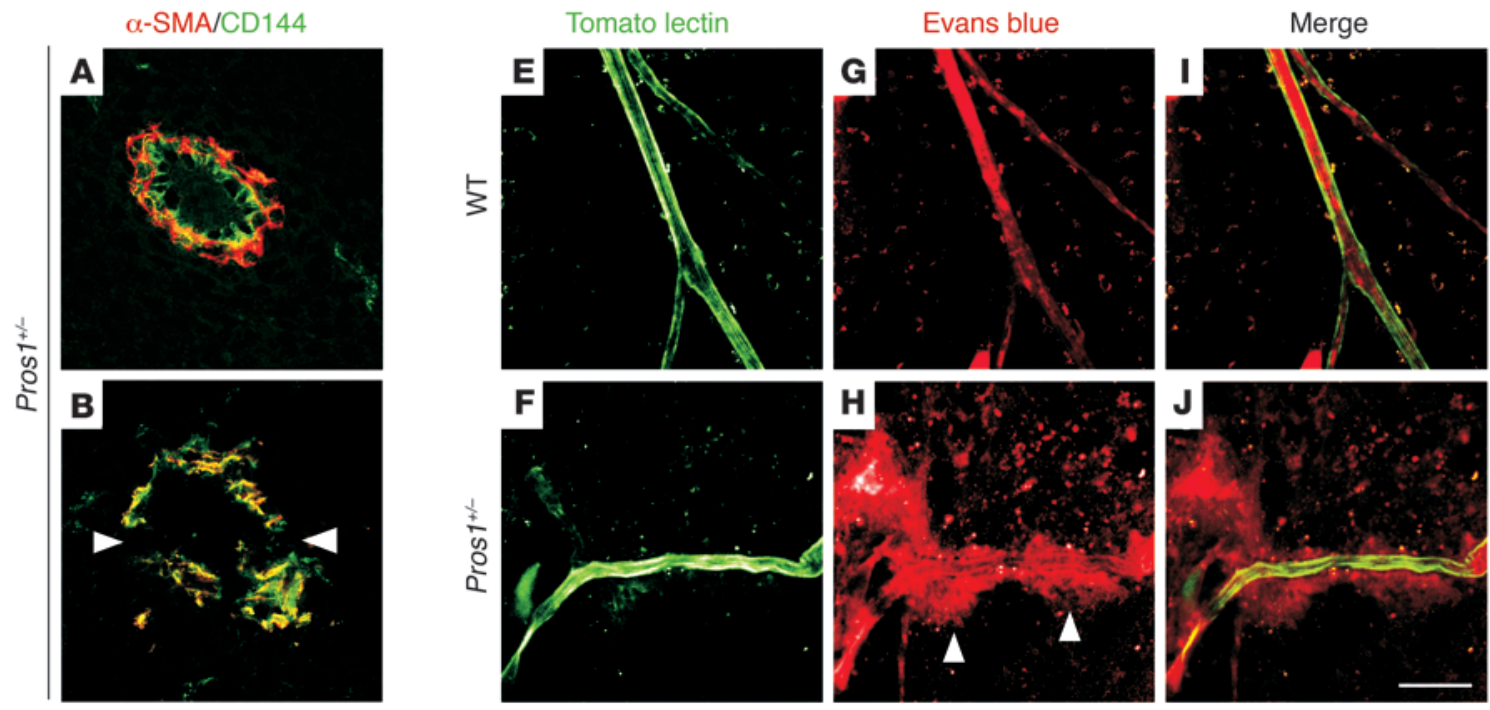
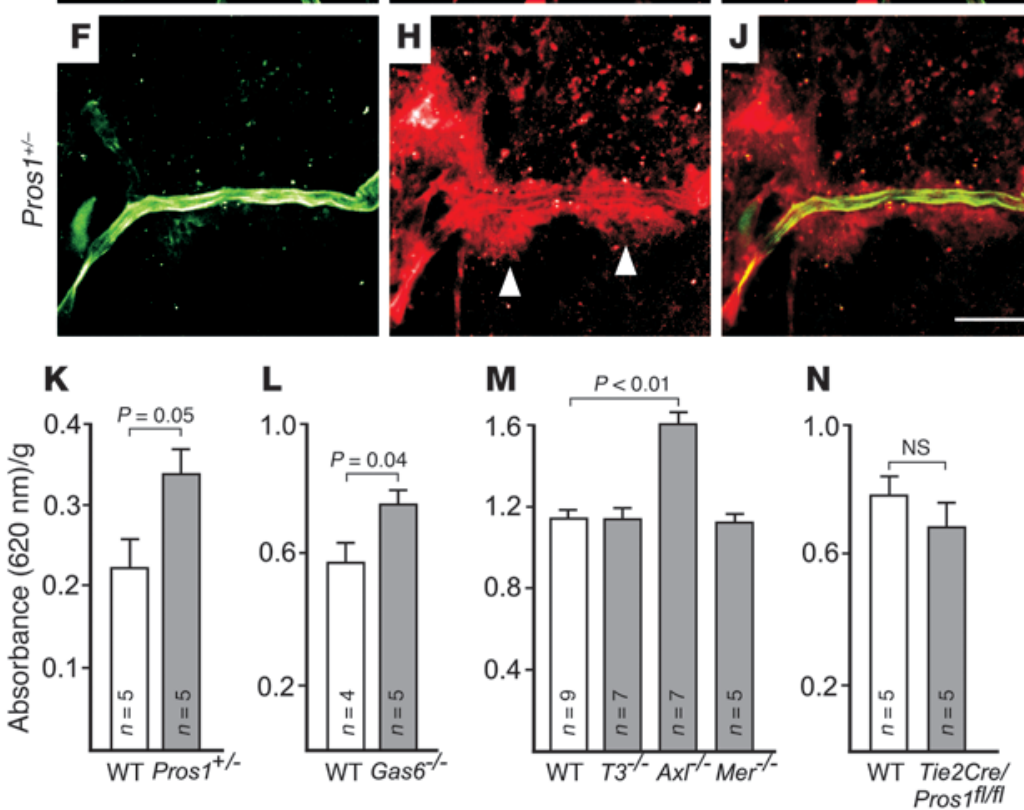

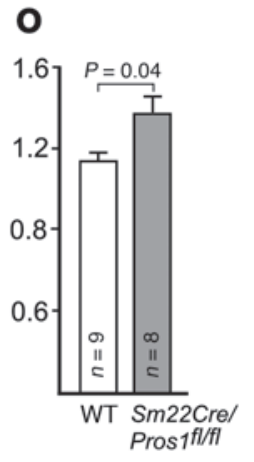

\section{Figure 7}

Defective vasculature in Pros 1+/- heterozygotes and other mutants. (A and B) Two vessels, one aberrant and one normal, from the same Pros $1^{+/-}$ embryo. Normal vessels (A) show discrete layers of luminal ECs and outer VSMCs, visualized by staining for CD144/VE-cadherin (green) and $\alpha$-SMA (red). Defective vessels (B) show nonuniform $\alpha$-SMA staining and intermixing of endothelial and smooth muscle layers, with break points (arrowheads). (C and D) Muzzles (C) and intestines (D) of wild-type (left) and Pros $1^{+/-}$adult mice, 1 hour after injection with $0.1 \%$ EB. (E-J) FITC-conjugated tomato lectin (green; $\mathbf{E}$ and $\mathbf{F}$ ) was injected into the tail vein of adult mice together with $\mathbf{E B}$ (red; $\mathbf{G}$ and $\mathbf{H}$ ). Tomato lectin labels vascular ECs. EB binds serum albumin and is confined to the interior of intact vessels; in leaky vessels, the dye leaches into tissue parenchyma. (E and G) Pros1+/+ brain vasculature maintains EB (red) within vessels (green). (F and $\mathbf{H})$ Leakage of EB (H, arrowheads) in Pros1+/- brain. (I and $\mathbf{J})$ Green and red channels of Pros $1^{+/+}$and Pros $1^{+/-}$vessels, respectively, merged. Scale bar in $\mathbf{J}$ applies to all immunofluorescence panels: $30 \mu \mathrm{m}$ in A and B; $100 \mu \mathrm{m}$ in E-J. (K-0) Modified Miles assays of EB penetration into liver parenchyma (see Methods) of WT mice versus

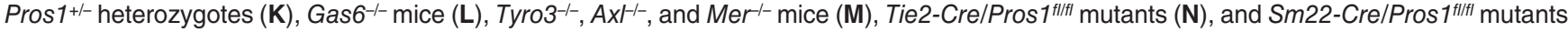
(O). EB (0.1\%) was injected for the measurements in $\mathbf{K}$, and $1 \%$ was injected for $\mathbf{L}-\mathbf{O}$. The cohort of WT mice is the same for $\mathbf{M}$ and $\mathbf{O}$. The number of mice analyzed per genetic group $(n)$ is indicated. Data are mean \pm 1 SEM.

externally visible signs of dye extravasation into multiple organs, including the gastrointestinal tract, ears, nose pad, paws, subcutaneous fascia, and brain. Examples of such EB permeation of the muzzle and intestine are shown in Figure 7, C and D. Tissue permeation was never observed in wild-type mice (Figure 7, C and $D$ ). We visualized dye leakage in brain sections by coinjection of EB with tomato lectin to label the ECs of blood vessels. Dye was always confined within tomato lectin-labeled vessels in sections of wild-type brain (Figure 7, E, G, and I; EB fluoresces red when excited at $550 \mathrm{~nm}$ ) but was frequently observed to leach out of vessels and into the brain parenchyma in adult $\operatorname{Pros}^{+/-}$mice (Figure $7, \mathrm{~F}, \mathrm{H}$, and $\mathrm{J}$ ).
These observations led us to perform a modified Miles assay (33-35) - a quantitative measurement of dye levels in tissues of mice injected with EB and then perfused 1 hour later with PBS. In this assay, dye levels are measured in tissues following overnight extraction in formamide (see Methods). We assayed the brain and liver of injected mice and performed the measurements in $\mathrm{Pros}^{+/-}$ and wild-type mice and also in 6 additional genotypes of interest with respect to ProS action in vessel development and function. Pros $1^{+/-}$heterozygotes consistently displayed higher levels of penetrating dye than did wild-type mice in the modified Miles assay (Figure 7K). However, given that these Pros $1^{+/-}$heterozygotes are subject to thromboses that may themselves compromise vessel 

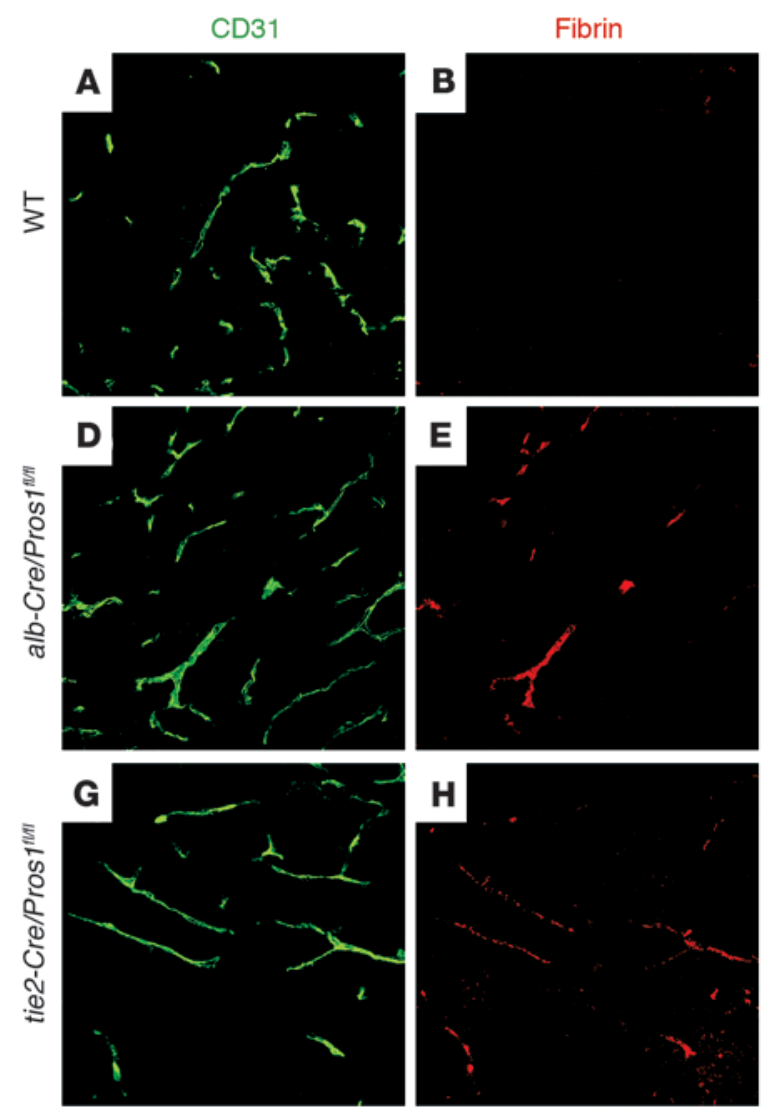
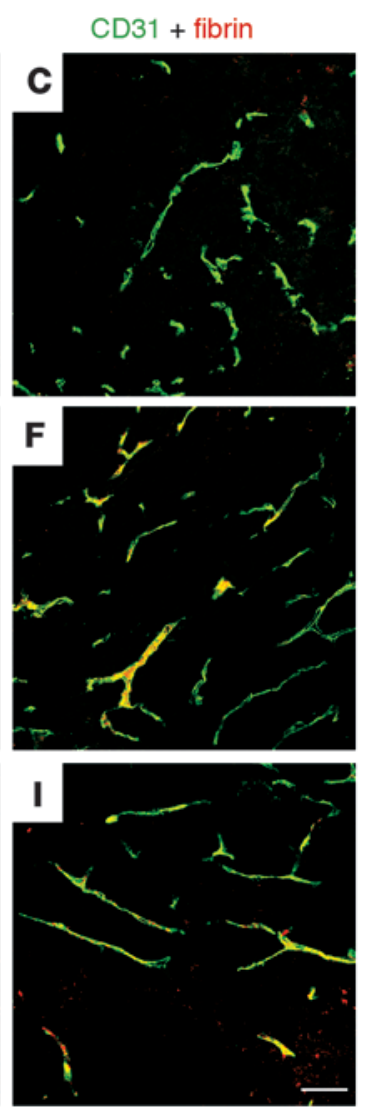

\section{Figure 8}

Coagulopathy without hemorrhage in $\mathrm{Alb}-\mathrm{Cre} /$ Pros $1^{\text {fl/fl }}$ and Tie2-Cre/Pros $1^{\text {fllfl }}$ embryos. CD31 visualization of ECs (green; left panels), fibrin visualization of clotted blood (red; middle panels), and merged CD31/fibrin images (right panels) in sections of E15.5 embryonic brain from WT (A-C), Alb-Cre/Pros1 $1^{\text {fllfl }}$ (D-F), and Tie2Cre/Pros $1^{\text {flffl }}$ mice (G-I). Scale bar in I applies to all panels: $50 \mu \mathrm{m}$.

chyma of Sm22-Cre/Pros $1^{f l / f l}$ mice, in which ProS is eliminated from VSMCs (Figure 7O). Taken together, these findings suggest that the vascular defects of the Pros 1 mutants may result from both (a) the thrombosis that develops in these mutants and (b) reduced ProS-dependent TAM receptor signaling.

Inactivation of the Pros1 gene in hepatocytes. We next assessed the extent to which the full spectrum of phenotypes evident in the complete Pros $1^{-/-}$knockouts might be phenocopied in mutants in which ProS was specifically eliminated from the liver. As noted above, most of the ProS present in the blood is thought to be synthesized and released into the circulation by hepatocytes. We therefore crossed mice carrying the floxed Pros 1 allele diagrammed in Figure $1 \mathrm{C}$ with an albumin-Cre driver line in which recombinase expression is restricted to hepatocytes (41). Any phenotypes that integrity and function, we also performed assays in Gas6 knockouts (36). Like ProS, Gas6 is a ligand for the TAM receptors (12), one of which - Axl - has been shown to be expressed by the VSMCs and ECs of the vasculature $(23,37)$. Unlike ProS, however, Gas6 plays no evident role as a blood anticoagulant, and Gas 6 mutants are not subject to thrombosis. Indeed, the Gas 6 knockouts have been shown to be protected from thrombosis (36), thus allowing us to assess the role of TAM signaling in vessel integrity per se. It was particularly interesting, therefore, that EB-injected Gas $6^{-/-}$ mice also displayed significantly elevated liver and brain dye levels relative to wild-type mice (Figure $7 \mathrm{~L} ; P=0.04$ and $P=0.025$ [data not shown], respectively).

Although Gas6 and ProS are both TAM receptor ligands, the only TAM receptor that has been reported to play a role in the vasculature is $\mathrm{Axl}$ (38). Consistent with these reports, we also measured significantly elevated EB permeation in liver isolated from EB-injected $A x l$ knockouts relative to wild-type but not in liver from either Tyro3 or Mer knockouts (Figure 7M; $P<0.001$ for $A x l$ ). Like the Gas 6 mutants and in contrast to the ProS mutants, Axlknockout mice have also been shown to be protected from thrombosis relative to wild-type mice (39).

Finally, we measured dye permeation in tissues of mouse lines in which we crossed our conditional Pros $1^{f l / f l}$ allele with Cre driver lines designed to eliminate ProS expression specifically in two different cell lineages. We observed no significant difference in dye penetration between wild-type and Tie2-Cre/Pros $1^{f l / f l}$ mice (Figure $7 \mathrm{~N}$ ), in which ProS expression is eliminated from ECs and hematopoietic lineage cells (ref. 40; see below). We did, however, detect significantly elevated EB permeation $(P=0.04)$ into the liver paren- develop in these mice should result solely from the loss of ProS in the liver, since ProS expression by vascular ECs, VSMCs, and all non-hepatocytes (e.g., megakaryocytes/platelets) remains unperturbed. Embryonic phenotypes in the Alb-Cre/Pros $1^{f / f l}$ mice cannot be compared directly with those of the EIIA-Cre/Pros $1^{f / f l}$ full knockouts, since recombination and gene inactivation triggered by the Alb-Cre transgene, while hepatocyte specific, is not complete in all hepatocytes until approximately 6 weeks after birth (42). After this time, however, direct phenotypic comparisons between these two strains can indeed be made (42).

We found that nearly all mice that carry the Alb-Cre transgene and that are also homozygous for the floxed Pros 1 allele are viable throughout embryogenesis and that most Alb-Cre/Pros $1^{f l / f l}$ embryos were indistinguishable from their wild-type littermates at E15.5 by gross examination (data not shown). We were unable to detect hemorrhages in most Alb-Cre/Pros $1^{f l / f l}$ embryos even at E17.5, a time at which hemorrhagic blood cells fill the tissues of all complete Pros $1^{-/-}$knockouts. All Alb-Cre/Pros $1^{f / f l}$ embryos also appeared to be nearly normal in terms of gross development at E17.5, by which time all of the complete knockouts had died.

Their viability notwithstanding, staining of sections of the E15.5-E17.5 Alb-Cre/Pros $1^{f l / f l}$ embryos with antibodies against CD31 and fibrin revealed the presence of focal fibrin deposition in blood vessels (Figure 8, D-F) in approximately $15 \%$ of embryos. Fibrin deposition was never detected in wild-type embryos (Figure 8, A-C). Unlike the situation in the complete knockouts, these fibrin clots appeared to be entirely contained within well-organized and normal-appearing vessels. When we examined Alb-Cre/ Pros $1^{f l f l}$ vessels in cross section, with antibodies against $\alpha$-SMA (for 

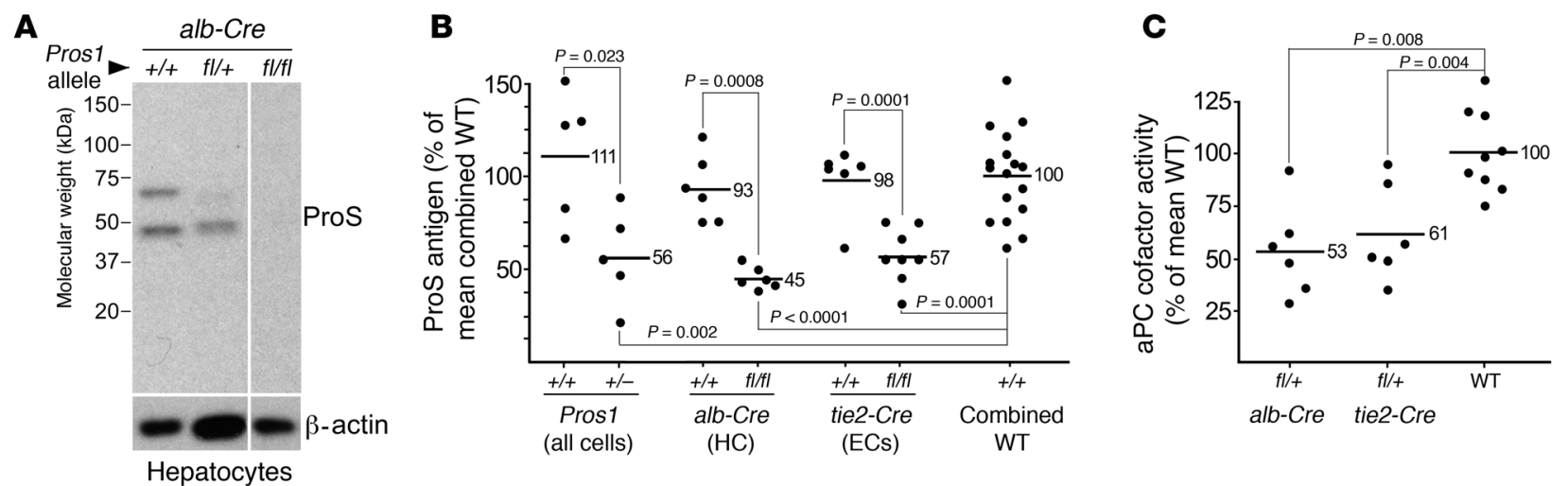

\section{Figure 9}

Elimination of ProS from hepatocytes in adult Alb-Cre/Pros $1^{\mathrm{fllfl}}$ mice and EC contribution of ProS to the circulation. (A) Immunoblots of ProS (top) and $\beta$-actin (bottom) of protein extracts of purified hepatocytes prepared from WT, Alb-Cre/Pros $1^{f l /+}$, and Alb-Cre/Pros $1^{f / l f l}$ adult mice. AlbCre/Pros $1^{t /+}$ and Alb-Cre/Pros $1^{f / f I}$ lanes were run on the same gel but were noncontiguous. (B) ELISA measurements of serum ProS levels in individual adult ( 8 weeks or older) mice of the indicated genotypes. (See Methods for ELISA/antibody protocols.) Levels in individual mice are expressed as a percentage of the mean value of measurements from 17 different wild-type mice (Combined WT). Mean values and $P$ values for comparisons between wild-type, EllA-Cre/Pros $1^{t / l+}$ heterozygous, and Alb-Cre/Pros $1^{f / l f l}$ and tie2-Cre/Pros $1^{f / l f l}$ homozygous sera are indicated. $\mathrm{HC}$, hepatocytes. (C) Measurement of aPC cofactor activity (prolongation of clotting time in seconds) in plasmas from mice of the indicated genotypes, in assays performed as those in Figure 5A (see Methods), expressed as percentage of WT. Mean values and $P$ values for comparisons between heterozygous Alb-Cre/Pros $1^{f /+}$, Tie2-Cre/Pros $1^{f / /+}$, and WT plasmas are indicated. Mean prolongation of clot time by aPC in WT mice (54.8 seconds) was taken as $100 \%$ aPC cofactor activity of ProS.

vascular smooth muscle) and CD31 (for vascular endothelia), we consistently observed a normal organization of smooth muscle and EC layers, with normal levels of $\alpha$-SMA and an intact vessel structure (data not shown).

Adult mice are viable in the absence of hepatocyte expression of ProS. As noted above, interpretation of the relatively modest embryonic phenotypes of the Alb-Cre/Pros $1^{f l / f l}$ mice is complicated by the relatively modest expression and activity of the Alb-Cre transgene during embryogenesis (43). However, the fact that recombination is complete by 6 weeks of age in this strain (42) allowed us to compare plasma ProS levels in adult Alb-Cre/Pros $1^{f l / f l}$ homozygous mice relative to wild-type mice. We first verified that ProS expression is indeed ablated in hepatocytes purified from Alb-Cre/Pros 1 fl/fl homozygotes by 8 weeks after birth (Figure 9A). We performed this analysis with hepatocytes isolated and purified from adult livers so as to eliminate other ProS-expressing cell types, such as megakaryocytes and ECs (see Methods). We found that the floxed Pros1 allele is indeed completely recombined, as assessed by Southern blotting of DNA prepared from the purified hepatocytes (data not shown); and, more importantly, that ProS expression was undetectable in protein extracts of these 8-week hepatocytes (cultured for 20 hours without serum), as assessed by Western blotting (Figure 9A).

We then used ELISA methods to measure circulating ProS in individual adult wild-type and Alb-Cre/Pros $1^{f l f l}$ homozygous mice. Although there is wide variation in ProS levels among individual mice (and humans) as a function of sex, age, circadian rhythm, and general physiology, these measurements nonetheless unambiguously demonstrated a significant reduction in blood-borne ProS, with circulating ProS levels in serum being reduced to approximately $45 \%$ of wild-type in adult Alb-Cre/Pros $1^{f l / f l}$ homozygotes (Figure 9B). We also detected a reduction in aPC cofactor anticoagulant activity when we performed in vitro assays of plasmas from Alb-Cre/Pros $1^{f l+}$ heterozygous mice relative to wild-type (Figure 9C), which was proportionally larger than the reduction in homozygote serum ProS protein measured by ELISA (Figure 9B). These results are consistent with the conclusion that (a) hepatocyte production accounts for approximately $55 \%$ of the ProS that appears in mouse blood; (b) other cells, in addition to hepatocytes, must contribute to the ProS present in the circulation; and (c) mice are viable as adults in the absence of any hepatocyte expression of the Pros 1 gene.

Vascular ECs secrete bioactive ProS into the circulation. We used a third transgenic Cre driver line, in which expression of the recombinase is targeted specifically to ECs and hematopoietic lineage cells (e.g., macrophages and DCs) by promoter elements of the Tie2 (angiopoietin receptor) gene (40), to assess the importance of EC-derived ProS to circulating ProS levels, blood coagulation, and vessel development. Unlike the Alb-Cre transgene, the Tie2-Cre driver yields complete recombination and gene inactivation in ECs at early embryogenesis. Tie2-Cre/Pros $1^{f / f l}$ mice were fully viable as both embryos and adults. These normal phenotypes notwithstanding, staining of sections of E15.5 embryonic brain blood vessels with antibodies against CD31 and fibrin revealed the presence of readily detected punctate fibrin immunoreactivity in the Tie2-Cre/Pros $1^{f / f l}$ vessels (Figure 8, G-I), which was never seen in wild-type vessels (Figure 8, A-C). In contrast to the complete Pros 1 knockouts, however, these fibrin clots were not associated with complete occlusion of vessels or embryonic hemorrhages. Fibrin deposition in Tie2-Cre/ Pros $1^{\ell l / f l}$ vessels (Figure 8, G-I) was somewhat less pronounced than in Alb-Cre/Pros $1^{f l / f l}$ vessels at the same age (Figure 8, D-F).

ELISAs performed with sera from adult Tie2-Cre/Pros $1^{f / f l}$ homozygotes indicated that these mice also display a significant reduction in circulating ProS, with levels that were approximately 57\% relative to those of wild-type Tie2-Cre/Pros $1^{+/+}$mice (Figure 9B). Consistent with these reductions in circulating ProS, Tie2-Cre/Pros $1^{f / /+}$ heterozygote plasmas also displayed a significant reduction in aPC cofactor activity in in vitro clotting assays (Figure 9C). As for the Alb-Cre/Pros $1^{f l / f l}$ mice, this reduction in heterozygote plasma cofactor activity in vitro was proportionally larger than the reduction 
in homozygote serum ProS protein, as measured by ELISA (Figure 9B). (Why plasma aPC cofactor activity is consistently hypersensitive to reductions in measured serum ProS levels in these in vitro assays is at present unclear.) These results provide the first in vivo genetic evidence to our knowledge that ECs and hematopoietic lineage cells (such as circulating macrophages and DCs) make a substantial contribution to the level of ProS in the circulation. They have significant implications for the biosynthesis, action, and potential manipulation of ProS and other clotting pathway components that are known to be expressed by vascular ECs.

\section{Discussion}

The phenotypes that appear in the complete Pros $1^{-/-}$mutants highlight a critical role for ProS in blood coagulation. Although aPC cofactor activity is indeed reduced by approximately 50\% in Pros $1^{+/-}$ plasma (Figure 5A), aPC-independent anticoagulant activity is also reduced (Figure 5, B-D). Thus, the in vivo phenotypes observed in Pros $1^{-/-}$mutants may reflect both aPC-dependent and aPC-independent effects on thrombosis. There are two conflicting reports as to whether ProS acts as a cofactor to TFPI during inhibition of extrinsic FXase $(44,45)$. Both studies used ProS that was deficient in $\mathrm{Zn}^{2+}$ and was therefore likely to also be deficient in its ability to inhibit prothrombinase, while we find that most of the ProS in plasma contains $\mathrm{Zn}^{2+}$ and efficiently inhibits prothrombinase (46). The assays we developed for ProS direct activity (Figure 5) use a prothrombinase stimulus and are unaffected by a neutralizing antibody against TFPI. Biochemical analysis of the $\operatorname{Pros}^{+/-}$heterozygotes therefore provides genetic evidence that ProS may have a direct anticoagulant function in the blood coagulation cascade.

The results detailed above also support a potential role for ProS in vascular development and function that may be independent of blood coagulation and PC. While $\mathrm{PC}^{-/-}$mice die within the first hours after birth due to coagulopathy, these mice nonetheless develop relatively normally through to the end of embryogenesis, with only scattered microvascular thromboses in the brain (47). In contrast, Pros $1^{-1-}$ mice display massive blood clots at mid-embryogenesis, coupled with severe hemorrhages that lead to embryonic lethality (Figures 2-4). These defects are associated with a wide range of secondary developmental anomalies (Figure 2D), none of which are apparent in the $P C^{-/-}$knockouts (47). It is possible that the differences in severity between the Pros 1 and $P C$ mouse knockouts may be explained by a maternal transfer of PC to the embryo during development. Such maternal rescue obviously does not occur to any meaningful extent for ProS in the Pros $1^{-/-}$mice (Figures 2 and 3 ). The potential maternal transfer of PC is at present unresolved: PC has been shown to be transported across the adult mouse blood-brain barrier via the endothelial PC receptor (48), but in in vitro isolated placental cotyledon perfusion experiments, von Dadelszen and colleagues found that PC neither crosses nor is degraded by the human placenta (49).

The potential maternal transfer of PC notwithstanding, the vessel permeability defects seen in the $\operatorname{Pros}^{+/-}, \mathrm{Gas}^{-/-}, A x \mathrm{I}^{\mathrm{I}^{-}}$, and Sm22-Cre/Pros $1^{f l / f l}$ mice, but not in $\mathrm{Tyro3}^{-/-}$or $\mathrm{Mer}^{-/}$mice, are all consistent with the possibility that ProS also regulates vessel development and functional integrity via its ability to bind to and activate the TAM receptor Axl in VSMCs and ECs of the vasculature. While blood flow is instructive to vessel development $(30,50)$ and thromboses often lead to secondary defects in vessel integrity (29), our results suggest that vascular dysgenesis in the Pros $1^{-/-}$mice may not be entirely secondary to vessel occlusion or compromised hemodynamics. Both ProS and its closely related TAM ligand Gas6 are produced by vascular ECs and VSMCs (refs. 12, 17, 20, 51, 52; and our results); Axl is also expressed by VSMCs $(38,53)$, and ProS is a demonstrated mitogen for cultured VSMCs (21). At the same time, the expression of Axl in the vasculature is markedly upregulated after injury $(23,54)$. The Axl and Gas6 knockouts - but not the Tyro3 or Mer knockouts - also display vessel permeability defects (Figure 7, L and M), as do the Sm22-Cre/Pros $f^{f / f l}$ mice, in which ProS expression is eliminated in VSMCs (Figure 7O). (Frequent brain hemorrhages have also previously been reported in mice mutant for all 3 TAM receptors [refs. 14, 15].) Vessel permeability defects in the Gas 6 and Axl knockouts cannot be explained by thrombosis, since both of these mutants are less - not more - prone to thrombotic events than are wild-type mice $(36,39)$. Protection from thrombosis in these mutants is thought to result from the loss of Gas6/Axl signaling in platelets, where this signaling appears to play a role in thrombus stabilization (36, 39). Together, all of these data suggest that ProS action during vessel development and homeostasis may be mediated in part by its binding to and activation of Axl expressed by VSMCs. Our data on this point are indirect, however, and although we consider it unlikely, it remains possible that all of the vascular defects we document in the Pros 1 mutants are entirely secondary to thrombosis. We anticipate that additional TAM-dependent roles for ProS can now be investigated in diverse cell types through the use of cellspecific Cre drivers in combination with our floxed Pros 1 allele.

With respect to our findings of altered blood coagulation profiles in the Pros 1 mutants, a recent report by Saller and colleagues (55) also describes the generation of Pros $1^{+/-}$and Pros $1^{-/-}$mice. These mutant lines display blood coagulation defects very similar to those we describe. Consistent with our data, the Pros $1^{+/-}$heterozygotes also show enhanced sensitivity to tissue factor-induced venous thromboembolism (55).

Our use of differential Cre drivers to extend the analysis of coagulation defects beyond the complete Pros 1 knockouts provides new insights into the sites of synthesis and action for the ProS that appears in the circulation. Although ProS has been shown to be produced by ECs in culture $(17,18)$, most attention has been focused on the production of this protein and other components of the clotting cascade by hepatocytes of the liver (7). The extent to which vascular ECs represent a biologically significant source for circulating ProS in vivo has not been assessed genetically. We demonstrate that adult Alb-Cre/Pros $1^{f l / f l}$ homozygotes can, remarkably, survive in the absence of any detectable hepatocyte expression of the Pros 1 gene. Approximately $45 \%$ of normal circulating ProS remains in the absence of hepatocyte-derived ProS (Figure 9B). Our results with the Tie2-Cre/ $\operatorname{Pros} 1^{f l / f l}$ homozygotes (Figure 9B) further indicate that much of this residual ProS is produced by ECs, macrophages, and DCs and that this level of anticoagulant activity is sufficient for viability. Hereditary ProS deficiency is a major risk factor for DVT and other thrombotic events, and there are more than 200 disease-predisposing Pros 1 mutations identified in humans. Our findings suggest that in addition to hepatocytes, vascular ECs, which are readily accessed via the circulation, may be especially favorable cellular targets for gene therapy interventions designed to correct genetic or acquired defects in ProS or other regulators of blood coagulation.

\section{Methods}

Generation of Pros1-knockout mice. The murine Pros1 gene was cloned from a 129s6/SvEvTAC spleen genomic DNA BAC library (CHORI), using a 
cDNA probe. A targeting vector (TV) was constructed by cloning a Pros 1 genomic fragment of $16.7 \mathrm{~kb}$ spanning exons $11-15$ into pBlueScript (Stratagene), utilizing the recombineering technique (56). The $5^{\prime}$ homology arm (HA) was PCR amplified with the following primers: 5 '-GTGGCCCGCATATAGAAGACC- $3^{\prime}$ and $5^{\prime}$-TTCACCTTATCTCCCGTCCCTT- ${ }^{\prime}$; and the following primers were used to amplify the 3 ' HA: $5^{\prime}$-AAATCGGATGGACTACAGAAGAAG-3' and 5'-ATTGAGGACACATGCGGATTTCTA-3'. The $5^{\prime}$ loxP site was inserted within the PL452 cassette immediately downstream of the $5^{\prime} \mathrm{HA}$, and the $3^{\prime}$ loxP site was inserted within the PL451 cassette, immediately upstream of the $3^{\prime}$ HA. PstI and BglI sites were introduced into the $5^{\prime} \operatorname{lox} P$ and the $3^{\prime} \operatorname{lox} P$ sequences, respectively, to allow for genomic screening of loxP sites. A neomycin resistance (neoR) gene was cloned with the $3^{\prime}$ loxP and was used for positive selection of ES cell clones. The TV was linearized with SacII and electroporated into mouse 2A ES cells. ES cells heterozygous for targeted recombination at the Pros 1 locus were used to generate chimeric animals. A chimeric germline-transmitting male was bred to EIIA-Cre homozygous (28) females to generate an $\mathrm{F}_{1}$ colony of $\operatorname{Pros} 1^{+/-}$heterozygous mice. Hepatocyte-, endothelium-, and vascular smooth muscle-specific inactivation of Pros 1 was achieved by cross-breeding Alb-Cre, Tie2-Cre, and SM22-Cre transgenic mice (The Jackson Laboratory) with $\operatorname{Pros} 1^{1 / f l}$ mice, respectively. In contrast to $\operatorname{Pros} 1^{+/-}$and Pros $1^{-/-}$mice, all hybrid Cre/Pros $1^{f / f l}$ lines were obtained at the expected Mendelian frequencies. All experimental procedures with mice described in this article were reviewed and approved by the Salk Institute Animal Care and Use Committee.

DNA analysis. Genotyping of DNA from adult mouse tails was performed by PCR designed to span the $5^{\prime}$ loxP and the $3^{\prime}$ neoR sequences. 100- and 200-bp differential PCR products were generated for the $5^{\prime}$ region of the wild-type and targeted alleles, respectively. HpaI digests of genomic DNA yielded a differential restriction pattern of $14 \mathrm{~kb}$ for the wild-type Pros 1 allele versus $7.5 \mathrm{~kb}$ for the knockout allele, detected by Southern blotting using a $5^{\prime}$ external probe. PCR reactions were also performed to verify loss of neoR sequences upstream of the $3^{\prime}$ loxP sequence after Cre-mediated excision. Routine genotyping was performed by Transnetyx Inc., utilizing a quantitative PCR (qPCR) reaction specifically designed to detect all allelic isoforms generated for the Pros1 gene.

qPCR. Levels of Pros 1 mRNA were measured by qPCR from embryonic liver and brain tissue, using the following primers: exons $4 / 5$ (nontargeted region): forward, $5^{\prime}$-TTCCGTGTTGGCTCATTCC- $3^{\prime}$ and reverse, 5'-TTGGTCTGAGATGGCTTTGACA-3'; exons 13/14 (targeted region): forward, $5^{\prime}$-GCACAGTGCCCTTTGCCT-3' and reverse, 5' -CAAATACCACAATATCCTGAGACGTT-3'; GAPDH: forward, 5'-TCCCACTCTTCCACCTTCGA-3' and reverse, 5'-AGTTGGGATAGGGCCTCTCTT-3'.

Protein analysis. Total tissue protein extracts were prepared from adult wild-type and Pros $1^{+/-}$livers by sonication in lysis buffer $(50 \mathrm{mM}$ Tris- $\mathrm{HCl}$, pH 7.5, $150 \mathrm{mM} \mathrm{NaCl}, 1 \%$ Triton X-100, 0.5\% NP-40, 0.1\% SDS, $0.5 \mathrm{mM}$ EDTA), supplemented with Complete Protease Inhibitor Cocktail (Roche). Lysates were incubated on ice for 30 minutes and centrifuged for 20 minutes. Equal amounts of protein were loaded on 3\%-8\% gradient Tris-Acetate gels (Invitrogen). After electrophoresis, proteins were transferred to Imobilon P membranes (Millipore) and blocked in blocking buffer (3\% BSA in $150 \mathrm{mM} \mathrm{NaCl}$ and $0.1 \%$ Tween-20 [TBST]) for 1 hour at room temperature. The membranes were then incubated overnight at $4^{\circ} \mathrm{C}$ in the presence of primary antibody. The following antibodies were used: rabbit anti- $\beta$-actin (1:1,000; Cell Signaling Technology) and rabbit anti-ProS, generated against a peptide within the thrombin-sensitive region $(1: 1,000$; catalog AB15928; Millipore). Membranes were washed 3 times for 5 minutes in TBST and incubated with an HRP-conjugated anti-rabbit secondary antibody (1:5,000, Amersham) in blocking buffer for 1 hour at room temperature and developed with an ECL reagent prepared in-house.
Primary hepatocyte isolation and culture. Hepatocytes were purified from Alb-Cre ${ }^{+} / \mathrm{ProS}^{+/+}$(wild-type), Alb-Cre ${ }^{+} / \mathrm{ProS}^{f /+}$ (heterozygous), and $\mathrm{Alb}-\mathrm{Cre}^{+} /$ $\operatorname{ProS}^{\ell / f l}$ (knockout) mice at age 8 weeks and 1 day. Mice were deeply anesthetized by an intraperitoneal injection of $1 \mathrm{mg} / \mathrm{ml}$ xylazine, $10 \mathrm{mg} / \mathrm{ml}$ ketamine; $250 \mu \mathrm{l} /$ mouse. The abdominal cavity was opened and the livers perfused directly through the inferior vena cava with $250 \mathrm{ml}$ wash buffer (1× HBSS [Invitrogen]; $50 \mathrm{mM} \mathrm{HEPES,} 5 \mathrm{mM}$ EGTA; 10,000 U/ml heparin) at a rate of $16 \mathrm{ml} / \mathrm{min}$, using a $25 \mathrm{G}$ needle. The portal vein was immediately cut open to relieve pressure. Immediately thereafter, $50 \mathrm{ml}$ digestion solution was perfused ( $1 \times$ HBSS, $50 \mathrm{mM} \mathrm{HEPES,} 5 \mathrm{mM} \mathrm{CaCl} 2,0.3 \mathrm{mg} / \mathrm{ml}$ collagenase IV [Sigma-Aldrich]). The liver was excised into wash buffer and teased apart with forceps to release hepatocytes. Cells were filtered through a $250-\mu \mathrm{m}$ mesh, pelleted at $60 \mathrm{~g}$ for 2.5 minutes, and resuspended in $25 \mathrm{ml}$ plating medium (Medium 199 [Invitrogen], 10\% FBS, $1 \times$ penicillin/streptomycin, $1 \times$ GlutaMAX [Invitrogen], $1 \times$ Fungizone). A final centrifugation through a $0.9 \%$ Percoll/HBSS (GE Healthcare) solution ( $60 \mathrm{~g}$ for $2.5 \mathrm{~min}$ utes) resulted in a pellet of purified hepatocytes. Cells were resuspended in growth medium, and $5 \times 10^{5}$ cells were plated on a 5 -cm tissue culture dish and allowed to adhere for 4 hours in a $5 \% \mathrm{CO}_{2} / 37^{\circ} \mathrm{C}$ incubator, after which the medium was replaced with serum-free medium (Medium 199, 1× penicillin/streptomycin, $1 \times$ GlutaMAX, $1 \times$ Fungizone) and the cells grown for 20 hours. Remaining hepatocytes were pelleted and used for genomic DNA extraction, using standard methods, followed by Southern blot analysis.

Protein extraction from purified hepatocytes. Cells were washed 3 times with ice-cold PBS and lysed for 3 minutes in $0.5 \mathrm{ml} 1 \times$ RIPA buffer $(25 \mathrm{mM}$ Tris pH 7.5; 150 mM NaCl; $1 \%$ NP-40; $1 \% \mathrm{Na}$ deoxycholate; $0.1 \%$ SDS) supplemented with Complete Protease Inhibitor Cocktail (Roche). Cells were scraped and placed in an Eppendorf tube on ice for 20 minutes to allow for further lysis, followed by a 15 -minute centrifugation at 15,000 g $(7-\mathrm{cm}$ rotor radius at $14,000 \mathrm{rpm}) / 4^{\circ} \mathrm{C}$. The lysate (supernatant) was aliquoted, transferred to fresh tubes, and stored at $-20^{\circ} \mathrm{C}$. Equivalent amounts of protein were loaded onto a $7 \%$ Tris-Acetate Protein gel (Invitrogen) according to manufacturer's instructions. Proteins were blotted onto a PVDF membrane (Millipore), blocked with 5\% milk/TBST for 1 hour at room temperature, reacted with primary antibodies overnight at $4^{\circ} \mathrm{C}$, and developed as detailed above.

Dye assessment of vessel integrity. Adult wild-type and Pros $1^{+/-}$mice were anesthetized by isoflurane inhalation. Two hundred microliters of a solution containing $0.1 \mathrm{mg} /$ mouse each of FITC-conjugated tomato lectin (Lycopersicon esculentum; Sigma-Aldrich) and EB/saline was injected into the tail vein and allowed to circulate for 1 hour, after which the animals were sacrificed. The brain was acutely isolated and coronally sectioned. Brain sections were immediately observed with a confocal microscope. Mice were observed for blue staining in brain tissue and internal organs.

Quantitative vascular permeability assay. We performed a modified version of the Miles assay (33). The Miles assay is based on the fact that EB that is introduced into the circulation binds to endogenous serum albumin, and it is used as a tracer to assay macromolecular leakage from peripheral vessels. Modified Miles assays were performed as described previously (34, 35). Briefly, $100 \mu \mathrm{l} \mathrm{EB}$ solution (Sigma-Aldrich), either $0.1 \%$ or $1 \%$ in $0.9 \%$ $\mathrm{NaCl}$, was injected into the tail vein of anesthetized mice and allowed to circulate for 1 hour. A minimum of 4 mice per genotype were injected, along with control WT mice from the same genetic background. Mice were then deeply anesthetized and perfused with PBS. The brain and a sample of the liver were excised and blotted on $3 \mathrm{M}$ tissue paper, and the wet weight was recorded. Tissues were then cut into approximately 2 -mm-thick slices, and each tissue was immersed in $2 \mathrm{ml}$ formamide and incubated overnight at $65^{\circ} \mathrm{C}$ to allow for EB dye extraction. The absorbance of the extracted dye was measured with a spectrophotometer at $620 \mathrm{~nm}$. Absorbance values were within the linear range of a standard curve of EB diluted in for- 
mamide and were then divided by the wet weight of the tissue, to normalize for different sample sizes. Results are presented as weight-normalized absorbance units per gram tissue.

Histology and immunohistochemistry. Staged embryos (morning of vaginal plug was considered E0.5) were fixed overnight at $4^{\circ} \mathrm{C}$ in paraformaldehyde (4\% in PBS) and either embedded in paraffin and cut at $4 \mu \mathrm{m}$ or cryopreserved in $30 \%$ sucrose (overnight, $4^{\circ} \mathrm{C}$ ) and subsequently embedded in TFM (Electron Microscopy Sciences), frozen in prechilled isopentane, and cryosectioned at $10 \mu \mathrm{m}$. Fresh-frozen tissue was snap-frozen in TFM as described, postfixed in ice-cold methanol, and processed for immunohistochemistry. Sections were blocked in blocking buffer $(5 \%$ NGS, $0.1 \%$ Triton X-100 in PBS) for 1 hour at room temperature, incubated with primary antibodies overnight at $4{ }^{\circ} \mathrm{C}$, washed 3 times in PBS, incubated with a secondary antibody (1:200 dilution in blocking buffer) for 1 hour at room temperature, washed 3 times, Hoechst stained, and mounted. E9.5 and E13.5 embryos and yolk sacs were fixed in Dent's fixative (methanol/DMSO, 4:1) overnight at $4^{\circ} \mathrm{C}$. Antibodies used were rat anti-mouse CD31/PECAM-1 (BD Biosciences - Pharmingen), 1:100; rat anti-mouse CD144/VE-cadherin (BD Biosciences - Pharmingen), 1:100; and mouse monoclonal anti-mouse $\alpha$-SMA (Sigma-Aldrich), 1: 7,500. $\mathrm{H} \& \mathrm{E}$ and differential Carstairs staining (57) designed to stain fibrin in magenta-purple, free blood cells in yellow-orange, and collagen in blue, was performed on $4-\mu \mathrm{m}$ paraffin sections; thin sections $(1 \mu \mathrm{m})$ of perfused ( $1 \% \mathrm{PFA} / 2 \%$ glutaraldehyde) embryos were processed for EM. Perfusion of embryos was performed immediately after their isolation. Embryos were pinned down, their hearts exposed, and perfusate was injected intracardially using a syringe with a $27 \mathrm{G}$ needle.

Blood analysis. Adult Pros $1^{+/-}$heterozygotes were anesthetized with $0.6 \mathrm{ml}$ of $2.5 \%$ Avertin in saline. Blood was drawn by cardiac puncture from the right ventricle with a $25 \mathrm{G}$ needle and immediately mixed, by 5 gentle inversions, with $3.8 \%$ sodium citrate as anticoagulant to achieve a final ratio of 9 parts whole blood to 1 part $\mathrm{Na}$ citrate. Plasma was isolated following centrifugation at $360 \mathrm{~g}$ (8-cm rotor radius at $2000 \mathrm{rpm})$ for 20 minutes at room temperature. For ELISAs, serum was prepared from blood collected by retro-orbital puncture. Aliquots of plasma or serum were frozen immediately at $-80^{\circ} \mathrm{C}$ prior to analysis.

Materials for coagulation and ELISA analyses. Human FV was purified and activated from plasma obtained after written informed consent of the blood donors, as described previously (58). Prothrombin, fibrinogen, and FXa were from Enzyme Research Laboratories; rabbit anti-human ProS was from Dako; secondary antibodies and peroxidase conjugate were from Pierce; $o$-phenylenediamine and $p$-amidino phenylmethylsulfonyl fluoride (pAPMSF) were from Sigma-Aldrich. Mouse aPC and rat neutralizing $\mathrm{mAb}$ TVM-1 against mouse PC were gifts from John Griffin and José Fernández (The Scripps Research Institute). Neutralizing mAb against TFPI was a gift from Diagnostica Stago and was found to shorten the clotting time of mouse plasma stimulated with tissue factor, lipids, and $\mathrm{Ca}^{2+}$. Conditioned medium containing rat ProS was a gift from Michael Hall and Barry Burgess (UCLA, Los Angeles, California, USA). Additional illustrations of the coagulation and ELISA assays are available in ref. 59.

ELISA for ProS in mouse sera. Nunc MaxiSorp microtiter plates (Fisher Scientific) were coated with $4 \mu \mathrm{g} / \mathrm{ml}$ rabbit anti-human ProS and blocked with I-block (Tropix). Pooled sera from WT mice was diluted from 1:50 to 1:1,600 in 0.05 M HEPES, $100 \mathrm{mM} \mathrm{NaCl}, \mathrm{pH} 7.4$ (HBS), containing $0.5 \%$ BSA and $0.01 \%$ Tween-20. Individual mouse sera were similarly diluted 1:100. These were incubated in the wells overnight at room temperature. The same buffer was used to dilute detection reagents; the same buffer without BSA was used for washes between steps. Bound ProS was detected with $5 \mu \mathrm{g} / \mathrm{ml}$ goat anti-human ProS IgG (prepared in house), followed by $0.5 \mu \mathrm{g} / \mathrm{ml}$ biotinylated mouse anti-goat IgG, $1 \mu \mathrm{g} / \mathrm{ml}$ streptavidin-
HRP, and $o$-phenylenediamine (Sigma-Aldrich). After color development $(\sim 4$ minutes), the reaction was quenched with an equal volume of $1 \mathrm{M} \mathrm{HCl}$; plates were read at $490 \mathrm{~nm}$. Unknowns were calculated by comparison to the standard curve. Data were normalized to the mean value for wild-type mice, which was taken as $100 \%$ ProS antigen.

FVa-based assay for aPC cofactor activity of ProS in mouse plasma. Plasma aliquots were thawed and treated with $20 \mu \mathrm{M}$ pAPMSF 20 minutes before use. Mouse plasma $(12 \mu \mathrm{l})$ was mixed with $2 \mu \mathrm{l}$ of $3 \mu \mathrm{M}$ prothrombin, $10 \mu \mathrm{l}$ of $9 \mathrm{mg} / \mathrm{ml}$ fibrinogen, and $43 \mu \mathrm{l}$ of $90 \mu \mathrm{M}$ phospholipid vesicles (20\% phosphatidyl serine, $80 \%$ phosphatidyl choline) in HBS $/ 0.5 \%$ BSA in cuvettes of an ST4 coagulometer (Diagnostica Stago). Mouse aPC ( $25 \mu \mathrm{l}$ of $2 \mu \mathrm{g} / \mathrm{ml}$ ) was added, followed by $33 \mu \mathrm{l}$ of $0.3 \mu \mathrm{g} / \mathrm{ml} \mathrm{FVa}$, each in $\mathrm{HBS} / 0.5 \%$ BSA. Mixtures were incubated at $37^{\circ} \mathrm{C}$ for 2 minutes with mixing prior to addition of $25 \mu \mathrm{l}$ of $50 \mathrm{mM} \mathrm{CaCl}_{2}$ to initiate clotting. Assays using human plasma and human aPC showed that prolongation of clot time was linear with increasing doses of plasma ProS mixed with ProS-depleted plasma and that the concentration of aPC used had little effect in ProS-depleted plasma. This linear behavior made it possible to measure relative differences in aPC cofactor activity among experimental mouse plasmas.

Assay for direct anticoagulant activity of ProS in mouse plasma. Mouse plasma $(15 \mu \mathrm{l})$ was thawed, pretreated for 20 minutes with pAPMSF, and mixed with $5 \mu \mathrm{l}$ of $3 \mu \mathrm{M}$ prothrombin and $6 \mu \mathrm{l}$ of $0.83 \mathrm{mg} / \mathrm{ml}$ neutralizing $\mathrm{mAb}$ against mouse aPC in HBS containing $0.5 \% \mathrm{BSA}$ and $5 \mathrm{mM} \mathrm{CaCl}_{2}$ for 5 minutes. A mixture of $\mathrm{FXa} / \mathrm{FVa} /$ phospholipid vesicles $/ \mathrm{CaCl}_{2}$ in $\mathrm{HBS} / 0.5 \%$ BSA was added to final concentrations of $20 \mathrm{pM} / 20 \mathrm{pM} / 25 \mu \mathrm{M} / 9 \mathrm{mM}$ in a volume of $15 \mu \mathrm{l}$, followed by $60 \mu \mathrm{l}$ of fluorogenic thrombin substrate Z-GGR-amino methyl coumarin (Bachem) in $\mathrm{HBS} / 0.5 \% \mathrm{BSA}, 5 \mathrm{mM} \mathrm{CaCl}_{2}$. To monitor thrombin generation, fluorescence was read every 20 seconds at an excitation wavelength of $360 \mathrm{~nm}$ and an emission wavelength of 460 $\mathrm{nm}$, as shown in Figure 5C. The first derivative of the fluorescence readings was calculated. Preincubation of mouse plasma with Dako anti-human ProS shifted the thrombin generation profiles of Figure 5C to the left and upward, or to a more procoagulant profile, consistent with responsiveness to ProS, and addition of concentrated rat recombinant ProS conditioned medium shifted the curve for normal mouse plasma to the right and downward, or to a less procoagulant profile (59).

Statistics. aPC cofactor activity of ProS and direct anticoagulant activity of ProS in wild-type and Pros $1^{+/-}$mouse plasmas were tested for normal distribution and then compared by a 2 -tailed $t$ test using Graph Pad Prism software. A $P$ value of 0.05 or less was considered significant for all experiments.

\section{Acknowledgments}

We thank Joseph Hash, Patrick Burrola, and Nadia Nashi for superb technical support; Kim Ravnskjaer for help with hepatocyte purification; and Carla Rothlin for fruitful discussions and critical reading. This work was supported by NIH grants AI077058 and EY017478 (to G. Lemke) and HL70002 and HL088375 (M.J. Heeb); and by the Lupus Research Institute (G. Lemke), the Stein endowment fund (M.J. Heeb), and a Hoffman Foundation Fellowship (T. BurstynCohen). We are grateful to José Fernández and John Griffin for the kind gifts of mouse aPC and antibody against mouse aPC and to Andrew Gale for anti-fibrin antibodies and helpful discussions.

Received for publication June 10, 2009, and accepted in revised form July 16, 2009.

Address correspondence to: Greg Lemke, MNL-L, The Salk Institute, 10010 N. Torrey Pines Rd., La Jolla, California 92037, USA. Phone: (858) 453-4100 ext. 1542; Fax: (858) 455-6138; E-mail: lemke@salk.edu. 
1. DiScipio, R.G., and Davie, E.W. 1979. Characterization of protein S, a gamma-carboxyglutamic acid containing protein from bovine and human plasma. Biochemistry. 18:899-904.

2. Garcia de Frutos, P., Fuentes-Prior, P., Hurtado, B., and Sala, N. 2007. Molecular basis of protein S deficiency. Thromb. Haemost. 98:543-556.

3. Walker, F.J. 1980. Regulation of activated protein $\mathrm{C}$ by a new protein. A possible function for bovine protein S. J. Biol. Chem. 255:5521-5524.

4. Heeb, M.J., Mesters, R.M., Tans, G., Rosing, J., and Griffin, J.H. 1993. Binding of protein S to factor Va associated with inhibition of prothrombinase that is independent of activated protein C. J. Biol. Chem. 268:2872-2877.

5. Heeb, M.J., et al. 1994. Protein S binds to and inhibits factor Xa. Proc. Natl. Acad. Sci. U. S. A. 91:2728-2732.

6. Marlar, R., and Neumann, G. 1990. Neonatal purpura fulminans due to homozygous protein C or protein S deficiencies. Semin. Thromb. Hemost. 16:299-309.

7. Ten Kate, M.K., and van der Meer, J. 2008. Protein S deficiency: a clinical perspective. Haemophilia. 14:1222-1228

8. Miyata, T., et al. 2008. Prevalence of genetic mutations in protein $\mathrm{S}$, protein $\mathrm{C}$ and antithrombin genes in Japanese patients with deep vein thrombosis. Thromb. Res. 124:14-18.

9. Bertolaccini, M., et al. 2003. Antibodies directed to protein $S$ in patients with systemic lupus erythematosus: prevalence and clinical significance. Thromb. Haemost. 90:636-641.

10. Fair, D.S., and Marlar, R.A. 1986. Biosynthesis and secretion of factor VII, protein C, protein S, and the Protein $\mathrm{C}$ inhibitor from a human hepatoma cell line. Blood. 67:64-70.

11. Lemke, G., and Rothlin, C.V. 2008. Immunobiology of the TAM receptors. Nat. Rev. Immunol. 8:327-336.

12. Stitt, T.N., et al. 1995. The anticoagulation factor protein S and its relative, Gas6, are ligands for the Tyro 3/Axl family of receptor tyrosine kinases. Cell. 80:661-670.

13. Rothlin, C.V., Ghosh, S., Zuniga, E.I., Oldstone, M.B., and Lemke, G. 2007. TAM receptors are pleiotropic inhibitors of the innate immune response. Cell. 131:1124-1136.

14. Lu, Q., and Lemke, G. 2001. Homeostatic regulation of the immune system by receptor tyrosine kinases of the Tyro 3 family. Science. 293:306-311.

15. Lu, Q., et al. 1999. Tyro-3 family receptors are essential regulators of mammalian spermatogenesis. Nature. 398:723-728.

16. Anderson, H.A., et al. 2003. Serum-derived protein $\mathrm{S}$ binds to phosphatidylserine and stimulates the phagocytosis of apoptotic cells. Nat. Immunol. 4:87-91.

17. Fair, D.S., Marlar, R.A., and Levin, E.G. 1986 Human endothelial cells synthesize protein S. Blood. 67:1168-1171.

18. Stern, D., Brett, J., Harris, K., and Nawroth, P. 1986. Participation of endothelial cells in the protein Cprotein S anticoagulant pathway: the synthesis and release of protein S. J. Cell Biol. 102:1971-1978.

19. Carmeliet, P. 2001. Biomedicine. Clotting factors build blood vessels. Science. 293:1602-1604.

20. Benzakour, O., and Kanthou, C. 2000. The anticoagulant factor, protein $\mathrm{S}$, is produced by cultured human vascular smooth muscle cells and its expression is up-regulated by thrombin. Blood. 95:2008-2014.

21. Gasic, G.P., Arenas, C.P., Gasic, T.B., and Gasic, G.J. 1992. Coagulation factors $\mathrm{X}, \mathrm{Xa}$, and protein $\mathrm{S}$ as potent mitogens of cultured aortic smooth muscle cells. Proc. Natl. Acad. Sci. U. S. A. 89:2317-2320.

22. Benzakour, O., et al. 1995. Evidence for a protein $\mathrm{S}$ receptor(s) on human vascular smooth muscle cells. Analysis of the binding characteristics and mitogenic properties of protein S on human vascular smooth muscle cells. Biochem. J. 308:481-485.

23. Melaragno, M.G., et al. 1998. Increased expression of Axl tyrosine kinase after vascular injury and regulation by $\mathrm{G}$ protein-coupled receptor agonists in rats. Circ. Res. 83:697-704.

24. Mackman, N. 2005. Tissue-specific hemostasis in mice. Arterioscler. Thromb. Vasc. Biol. 25:2273-2281.

25. Connolly, A.J., Ishihara, H., Kahn, M.L., Farese, R.V., Jr., and Coughlin, S.R. 1996. Role of the thrombin receptor in development and evidence for a second receptor. Nature. 381:516-519.

26. Carmeliet, P., et al. 1996. Role of tissue factor in embryonic blood vessel development. Nature. 383:73-75.

27. Ishiguro, K., et al. 2000. Complete antithrombin deficiency in mice results in embryonic lethality. J. Clin. Invest. 106:873-878.

28. Lakso, M., et al. 1996. Efficient in vivo manipulation of mouse genomic sequences at the zygote stage. Proc. Natl. Acad. Sci. U. S. A. 93:5860-5865.

29. Hahn, C., and Schwartz, M.A. 2009. Mechanotransduction in vascular physiology and atherogenesis. Nat. Rev. Mol. Cell Biol. 10:53-62.

30. May, S.R., Stewart, N.J., Chang, W., and Peterson, A.S. 2004. A Titin mutation defines roles for circulation in endothelial morphogenesis. Dev. Biol. 270:31-46.

31. Zhao, S., et al. 1995. Synergistic effects of fluid shear stress and cyclic circumferential stretch on vascular endothelial cell morphology and cytoskeleton. Arterioscler. Thromb. Vasc. Biol. 15:1781-1786.

32. St-Pierre, P., Bouffard, L., Papirakis, M.-E., and Maheux, P. 2006. Increased extravasation of macromolecules in skeletal muscles of the Zucker rat model. Obesity. 14:787-793.

33. Miles, A.A., and Miles, E.M. 1952. Vascular reactions to histamine, histamine-liberator and leukotaxine in the skin of guinea-pigs. J. Physiol. 118:228-257.

34. Satchi-Fainaro, R., et al. 2005. Inhibition of vessel permeability by TNP-470 and its polymer conjugate, caplostatin. Cancer Cell. 7:251-261.

35. Streit, M., et al. 2000. Thrombospondin-1 suppresses wound healing and granulation tissue formation in the skin of transgenic mice. $E M B O J$. 19:3272-3282.

36. Angelillo-Scherrer, A., et al. 2001. Deficiency or inhibition of Gas 6 causes platelet dysfunction and protects mice against thrombosis. Nat. Med. 7:215-221.

37. O’Donnell, K., Harkes, I.C., Dougherty, L., and Wicks, I.P. 1999. Expression of receptor tyrosine kinase Axl and its ligand Gas6 in rheumatoid arthritis: evidence for a novel endothelial cell survival pathway. Am. J. Pathol. 154:1171-1180.

38. Melaragno, M.G., Fridell, Y.-W.C., and Berk, B.C. 1999. The Gas6/Axl System: a novel regulator of vascular cell function. Trends Cardiovasc. Med. 9:250-253.

39. Angelillo-Scherrer, A., et al. 2005. Role of Gas6 receptors in platelet signaling during thrombus stabilization and implications for antithrombotic therapy. J. Clin. Invest. 115:237-246.

40. Kisanuki, Y.Y., et al. 2001. Tie2-Cre transgenic mice: a new model for endothelial cell-lineage analysis in vivo. Dev. Biol. 230:230-242.

41. Postic, C., et al. 1999. Dual roles for glucokinase in glucose homeostasis as determined by liver and pancreatic beta cell-specific gene knock-outs using Cre recombinase. J. Biol. Chem. 274:305-315.

42. Postic, C., and Magnuson, M.A. 2000. DNA excision in liver by an albumin-Cre transgene occurs progressively with age. Genesis. 26:149-150.

43. Miyatsuka, T., et al. 2003. Ectopically expressed PDX-1 in liver initiates endocrine and exocrine pancreas differentiation but causes dysmorphogenesis. Biochem. Biophys. Res. Commun. 310:1017-1025.

44. Hackeng, T.M., Sere, K.M., Tans, G., and Rosing, J. 2006. Protein S stimulates inhibition of the tissue factor pathway by tissue factor pathway inhibitor. Proc. Natl. Acad. Sci. U. S. A. 103:3106-3111.

45. Ndonwi, M., and Broze, G., Jr. 2008. Protein S enhances the tissue factor pathway inhibitor inhibition of factor Xa but not its inhibition of factor VIIa-tissue factor. J. Thromb. Haemost. 6:1044-1046.

46. Heeb, M.J., Prashun, D., Griffin, J.H., and Bouma, B.N. 2009. Plasma protein S contains zinc essential for efficient activated protein $\mathrm{C}$-independent anticoagulant activity and binding to factor $\mathrm{Xa}$, but not for efficient binding to tissue factor pathway inhibitor. FASEB J. In press.

47. Jalbert, L.R., et al. 1998. Inactivation of the gene for anticoagulant protein $\mathrm{C}$ causes lethal perinatal consumptive coagulopathy in mice. J. Clin. Invest. 102:1481-1488.

48. Deane, R., et al. 2009. Endothelial protein C receptor-assisted transport of activated protein $\mathrm{C}$ across the mouse blood-brain barrier. J. Cereb. Blood Flow Metab. 29:25-33.

49. von Dadelszen, P., et al. 2002. Activated protein $\mathrm{C}$ in normal human pregnancy and pregnancies complicated by severe preeclampsia: a therapeutic opportunity? Crit. Care Med. 30:1883-1892.

50. le Noble, F., et al. 2005. Control of arterial branching morphogenesis in embryogenesis: go with the flow. Cardiovasc. Res. 65:619-628.

51. Manfioletti, G., Brancolini, C., Avanzi, G., and Schneider, C. 1993 . The protein encoded by a growth arrest-specific gene (gas6) is a new member of the vitamin $\mathrm{K}$-dependent proteins related to protein S, a negative coregulator in the blood coagulation cascade. Mol. Cell. Biol. 13:4976-4985.

52. Nakano, T., et al. 1995. Vascular smooth muscle cell-derived, Gla-containing growth-potentiating factor for Ca-mobilizing growth factors. J. Biol. Chem. 270:5702-5705

53. Korshunov, V.A., Mohan, A.M., Georger, M.A., and Berk, B.C. 2006. Axl, a receptor tyrosine kinase, mediates flow-induced vascular remodeling. Circ. Res. 98:1446-1452.

54. Lutgens, E., et al. 2008. Genetic loss of Gas6 induces plaque stability in experimental atherosclerosis. J. Pathol. 216:55-63.

55. Saller, F., et al. 2009. Generation and phenotypic analysis of protein S-deficient mice. Blood. Online publication ahead of print. doi:0:blood-2009-03-209031v1.

56. Liu, P., Jenkins, N.A., and Copeland, N.G. 2003. A highly efficient recombineering-based method for generating conditional knockout mutations. Genome Res. 13:476-484.

57. Sheehan, D.C., and Hrapchak, B.B. 1980. Theory and practice of histotechnology. Battelle Press. Columbus, Ohio, USA. 218 pp.

58. Tans, G., et al. 1991. Comparison of anticoagulant and procoagulant activities of stimulated platelets and platelet-derived microparticles. Blood. 77:2641-2648.

59. Fernandez, J.A., et al. 2009. Species specific anticoagulant and mitogenic activities of murine protein S. Haematologica. In press. 